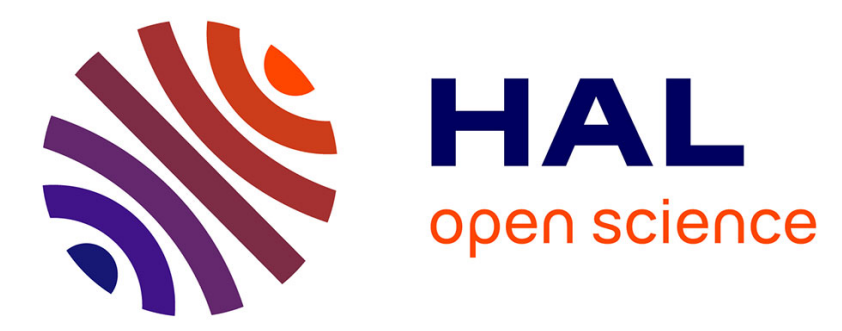

\title{
Determining the stress-strain behaviour at large strains from high strain rate tensile and shear experiments
}

\author{
J. Peirs, P. Verleysen, W. van Paepegem, J. Degrieck
}

\section{To cite this version:}

J. Peirs, P. Verleysen, W. van Paepegem, J. Degrieck. Determining the stress-strain behaviour at large strains from high strain rate tensile and shear experiments. International Journal of Impact Engineering, 2011, 10.1016/j.ijimpeng.2011.01.004 . hal-00816798

\section{HAL Id: hal-00816798 \\ https://hal.science/hal-00816798}

Submitted on 23 Apr 2013

HAL is a multi-disciplinary open access archive for the deposit and dissemination of scientific research documents, whether they are published or not. The documents may come from teaching and research institutions in France or abroad, or from public or private research centers.
L'archive ouverte pluridisciplinaire HAL, est destinée au dépôt et à la diffusion de documents scientifiques de niveau recherche, publiés ou non, émanant des établissements d'enseignement et de recherche français ou étrangers, des laboratoires publics ou privés. 


\section{Accepted Manuscript}

Title: Determining the stress-strain behaviour at large strains from high strain rate tensile and shear experiments

Authors: J. Peirs, P. Verleysen, W. Van Paepegem, J. Degrieck

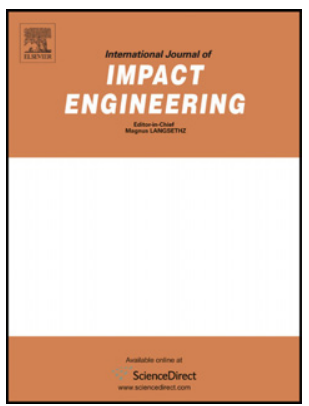

PII:

S0734-743X(11)00005-4

DOI:

10.1016/j.ijimpeng.2011.01.004

Reference: IE 1971

To appear in: International Journal of Impact Engineering

Received Date: 6 October 2010

Revised Date: 11 January 2011

Accepted Date: 18 January 2011

Please cite this article as: Peirs J, Verleysen P, Van Paepegem W, Degrieck J. Determining the stressstrain behaviour at large strains from high strain rate tensile and shear experiments, International Journal of Impact Engineering (2011), doi: 10.1016/j.ijimpeng.2011.01.004

This is a PDF file of an unedited manuscript that has been accepted for publication. As a service to our customers we are providing this early version of the manuscript. The manuscript will undergo copyediting, typesetting, and review of the resulting proof before it is published in its final form. Please note that during the production process errors may be discovered which could affect the content, and all legal disclaimers that apply to the journal pertain. 


\title{
Determining the stress-strain behaviour at large strains from high
}

\section{strain rate tensile and shear experiments}

\author{
J. Peirs, P. Verleysen, W. Van Paepegem and J. Degrieck \\ Ghent University, Department of Materials Science and Engineering, 9000 Gent, Belgium
}

\begin{abstract}
To characterise the high strain rate mechanical behaviour of metals, split Hopkinson bar experiments are frequently used. These experiments basically yield the force and elongation history of the specimen, reflecting not only the specimen material behaviour but also the specimen structural behaviour. Calculation of the real material behaviour from this global response is not straightforward, certainly for materials such as Ti6Al4V where due to low strain hardening, the specimen deformation is very inhomogeneous. However, for fundamental material research and constitutive material modelling, knowledge of the true effective stress versus plastic strain, strain rate and temperature is essential.

In this contribution, a combined experimental-numerical approach for extraction of the strain rate and temperature dependent mechanical behaviour from high strain rate experiments is presented. The method involves the identification of the material model parameters used for the finite element simulations. The technique is applied to determine the stress-strain behaviour of Ti6Al4V using both high strain rate in-plane shear and tensile test results. For the tensile tests, even stress-strain data beyond diffuse necking are retrieved. A comparison is made between the material behaviour extracted from the tensile and the shear experiments. The material behaviour is modelled with the Johnson-Cook constitutive relation. It is found that the simultaneous use of tensile and shear tests to identify the model parameters gives a more generally applicable model. Validation of the material model and the finite element simulations is done by local strain measurements in the shear and tensile test by means of digital image correlation.
\end{abstract}

Keywords - Hopkinson, Ti6A14V, high strain rate, digital image correlation, inverse method 


\section{Introduction}

The split Hopkinson bar (SHB) technique is well known for characterizing the high strain rate behaviour of materials in tension, compression and shear. The possibility to determine the stress and strain history in the specimen without direct measurement on the specimen itself is generally acknowledged to be one of the main advantages of the SHB technique compared to other high strain rate techniques. Therefore a homogeneous stress and strain distribution is assumed in the gage section of the specimen. Moreover, for tensile experiments, the deformation of the shoulders of the typically dogbone-shaped tensile specimen is assumed to be negligible. Recently, advanced full field strain measurements $[1,2]$ have shown that both assumptions are not obvious. The strain determined from the SHB measurements only corresponds with the local strain if the deforming section of the specimen is well defined. The actual distribution of the deformation is dependent on both the specimen geometry and the constitutive behaviour of the material. If an appropriate specimen geometry is used, for metals showing significant hardening, the measured stress-strain curve is still a good representation of the real material behaviour because the error made by neglecting the strain in the shoulders is compensating for the non-homogenous strain in the gage section [3]. On the other hand, for metals with low strain hardening, such as Ti6Al4V, no compensation occurs and the calculated strain is an underestimation of the actual strain reached. In addition, the true stress-strain behaviour cannot be assessed beyond diffuse necking which means that a large part of the plastic behaviour of the material remains unknown in materials with early necking. The plastic behaviour at high strains is however important in many practical applications such as metal forming operations. The limitation set by necking in tensile tests can be avoided by shear tests. However, determination of the material behaviour in shear tests is not obvious as well because there is no one-one relation between the measured displacement and the shear strain. Clearly, a method is needed for retrieving 
the true stress and strain state from tensile samples with large, inhomogeneous strains and shear samples.

Finite element simulations are a proven method to calculate the stress and the strain distribution in the test specimens. In this way a better insight into the relation between the material behaviour and structural response of the specimen is acquired. Finite element simulations were used for example by Bronkhorst [4] for hat-shaped specimen, Gilat [5] for torsion specimens, Verleysen [6] for tensile specimen, Rusinek and Klepaczko [7] for double-notched shear specimen, Dorogoy and Rittel [8] for SCS specimens, and many more. The validity of such simulations highly depends on the material model implemented in the FE model.

For material research, the development of dynamic material models and/or the identification of model parameters knowledge of the effective stress-strain behaviour as a function of strain rate and temperature is essential. Since SHB tests provide no more than the average stress and strain in the gage section of the specimen, a technique is needed to extract the local material behaviour from the global specimen response.

In the last decades, several approaches for extracting the local material behaviour from the global specimen response have been developed. An analytical method for obtaining static true stress-strain curves of metals was developed by Bridgman in 1952 [9]. The method is based on assumptions on the geometry of the diffuse neck and requires measurements of the radius of curvature of the neck and the width of the smallest cross section. For dynamic experiments however, these values are difficult to obtain. The method is also restricted to tension tests. For static tensile experiments, Zhang [10] proposed a method for specimens with a rectangular cross section based on the measured loadthickness curve.

More recently developed techniques make use of finite element simulations. These methods [11-13] typically involve an iterative optimization of the material model by minimizing the difference between the simulated and experimental load-displacement curves. A disadvantage of these methods 3 
is that only the average stress-strain curves are optimized and not the local ones. It is not excluded that different material models result in the same average load-displacement response of the specimen, or if a phenomenological model is used, that different parameter sets for the same model result in the same global stress-strain curve.

An alternative approach to obtain more accurately the local strain in the specimen uses optical (full field) strain measurements such as the moiré phase shifting and digital image correlation technique (DIC). No information however is obtained on the local stress. An overview of identification techniques based on full-field measurements has been recently published in [14].

Advanced techniques for effective stress-strain determination are based on a combination of FE simulations and DIC. Tao [15] developed an iterative procedure for quasi-static tensile tests. The stress correction applied for each iteration is based on the ratio between the experimentally measured (DIC) and FE computed average axial true stress-true strain curves. This method only takes into account the axial stress and strain components and its average values. In contrast, the local strain distribution is taken into account by the advanced method elaborated by Kajberg and Lindkvist [16] and Kajberg and Wikman [17]. The correction is done by minimizing an objection function which is a least-square functional with residuals based on the difference between experimental (DIC) and FEcalculated local displacements and strains. The correctness of the DIC strain measurement is crucial for the accuracy of this method and a very good synchronisation between the global test results, DIC measurements and FE calculations is required. These requirements are not easily achieved during dynamic experiments. Although, there is a fast technical evolution of high speed cameras, capturing sufficient, good quality, high resolution pictures during a dynamic experiment still remains a challenge. Furthermore, interpretation of the DIC results is not straightforward, errors can easily be introduced [18, 19].

In this work, an alternative, iterative experimental-numerical method is presented to extract the local high strain rate material behaviour, i.e. the effective stress and strain of Ti6Al4V. The method 4 
implicitly takes into account non-axial strain components, stress-strain and also temperature distribution in the specimen without the need of digital image correlation and is less complex and time consuming than the Kajberg method. Application is not restricted to dynamic tensile tests but also shear tests can be used. It is shown that the method is well suited to accurately calculate model parameters from the experimental behaviour. In this work the Johnson-Cook model is used but other material models could also be used. The Johnson-Cook parameters that are obtained during this procedure are more accurate than those obtained with methods that only use the average stress-strain curves because local adiabatic temperature increase, strain rate and stress triaxiality are taken into account. Application of the method to static experiments is possible too but less useful because the strain, strain rates and temperature are more homogeneous and other proven identification techniques exist for static experiments such as the ones described above.

Digital image correlation (DIC) and in-situ measurement of the transverse contraction of the tensile specimen are used as validation tools for the simulations. Furthermore, comparison of the results from the two experimental techniques extends the insight into the effect of the specimens' structural behaviour on the results.

The first part of the paper describes the experimental techniques and obtained results. The second part focuses on the material behaviour extraction method and validation of the model.

\section{Material and experimental observations}

\subsection{Material}

The investigated material is the titanium alloy Ti6Al4V (ASTM Grade 5) provided by TIMETAL. The alloy consists of a majority of hexagonal (HCP) $\alpha$-phase and a finely dispersed cubic (BCC) $\beta$ phase. The $\alpha$ - $\beta$ transformation temperature is $\pm 996^{\circ} \mathrm{C}$ which is well above the temperatures reached in our experiments by adiabatic heating. Although, twinning is acknowledged to be an important 
deformation mechanism in hep materials, it is generally not considered a major deformation mechanism in Ti6Al4V [20]. Specimens are cut by means of electrical discharge machining (EDM) from a $0.6 \mathrm{~mm}$ thin sheet. For the tensile and shear tests, specimens in the rolling (RD) and transverse (TD) direction are produced to study the anisotropic material behaviour.

\subsection{High strain rate tests}

For the tensile tests dogbone-shaped specimens are used with a gage length of $5 \mathrm{~mm}$ and a width of $4 \mathrm{~mm}$. The radius of the transition zones is $1 \mathrm{~mm}$ (Figure 1).

Figure 1: Tensile specimen geometry. The shaded parts are glued in slots of the Hopkinson bars.

For the shear tests, a purpose developed specimen is used. The in-plane shear specimen geometry is shown in Figure 2. Due to the particular geometry, optimized for the mechanical properties of Ti6Al4V, the tensile load imposed on the specimen is converted into a shear load on the material in the central shear region. The stress state in the small shear region is almost pure shear due to the nonaligned position of the notches [21]. The small dimensions together with the possibility to glue the specimen to the Hopkinson bars instead of fixing with a mechanical clamp make the specimen suitable for dynamic testing.

Figure 2: Shear specimen geometry. The shaded parts are glued in slots of the Hopkinson bars.

A shear test allows studying the material behaviour along a different loading path than in a tensile test. Compared to tensile tests, shear tests have several advantages. First, since no cross section reduction occurs in a shear specimen, a more stable deformation is obtained. Second, an unambiguous relation exists between true and engineering values of the stress. Third, damage growth is postponed because of the lower stress triaxiality in shear and, dependent on the material, the shear 
test can thus be used to characterize the behaviour at larger strains than in a tensile test [22]. Materials susceptible to shear localization, however, will fail at lower deformations. The latter is the case for Ti-6Al-4V. The main drawback is the more complicated relation between the structural and material response of the specimen. A local strain measurement or calculation, which is the subject of this study, is essential because the extent of the plastic region is even less well understood than for a tensile specimen.

Digital image correlation (DIC) is used to assess the local axial strain in the tensile specimen. Therefore, a fine speckle pattern is sprayed randomly on the specimen surface. Images with a resolution of $384 \times 192$ pixels and a frame rate of 31500fps are recorded with a Photron APX RS high speed camera. Synchronisation of the images with the strain gage measurements can be done by using a single trigger signal or by using the camera shutter pulse output. The non-commercial software MatchID is used to calculate the strain field from the images [18, 19].

The split Hopkinson tensile bar technique is used for high speed loading of the shear and tensile specimens. The small specimen is glued into slots between the input and output Hopkinson bars. A tensile loading wave generated at the free end of the input bar by impact of a projectile, propagates along the input bar towards the specimen. This wave interacts with the specimen and is partly reflected back into the input bar and partly transmitted into the output bar. The strain corresponding with the loading, reflected and transmitted wave $\left(\varepsilon_{\mathrm{i}}, \varepsilon_{\mathrm{r}}\right.$ and $\left.\varepsilon_{\mathrm{t}}\right)$ is measured by means of strain gages on the Hopkinson bars. From those waves, the total force and elongation history of the specimen can be determined, based on the principles of one-dimensional elastic-wave propagation in slender bars $[23,24]$. The set-up used in this study has aluminium (A15083) bars with lengths of $6 \mathrm{~m}$ and 3.125m, and a diameter of $25 \mathrm{~mm}$. Reliable tests require force equilibrium in the specimen. Although there is a relatively large impedance mismatch between the specimen and the bars, the finite rise time of the input wave has a very positive effect on the force equilibrium [25]: the force difference between the left and right hand sight of the specimen is below $1.5 \%$ after $10 \mu$ s. 


\subsection{Tensile test results}

Assuming that homogeneous stresses and strains are reached in the gage section of the tensile specimen, engineering values for the stress $\mathrm{s}$ and strain e can be calculated respectively by dividing the force by the cross sectional area and the elongation by the gage length. The strain consists of an elastic $e_{e}$ and a plastic $e_{p}$ component. The plastic component is calculated as $e_{p}=e-e_{y}-\left(s-s_{y}\right) / E$ with $s_{y}$ and $\mathrm{e}_{\mathrm{y}}$ the engineering values for the yield stress and strain. The average plastic true strain $\varepsilon_{\mathrm{p}}$ is then calculated from the plastic engineering strain $\mathrm{e}_{\mathrm{p}}: \varepsilon_{\mathrm{p}}=\ln \left(1+\mathrm{e}_{\mathrm{p}}\right)$. The true stress $\sigma$ is calculated from the engineering stress $\mathrm{s}$ by assuming conservation of volume during plastic deformation: $\sigma=\mathrm{s}\left(1+\mathrm{e}_{\mathrm{p}}\right)$. Important to note is that an error in e will cause an error in $\sigma$. The average plastic true stress versus true strain curves, represented in Figure 3, are calculated from the Hopkinson bar waves. The assumption of homogeneous stresses and strains is definitely not valid after necking. Therefore, for the material considered here, the curves are not correct for strains higher than 2 to 3 percent.

The behaviour of the material in the transverse and rolling direction is very similar. The only significant difference is found for the total elongation at fracture. Loaded in the transverse direction, the material fails almost $1.5 \%$ earlier. For the strain rates used (average values $\pm 400 \mathrm{~s}^{-1}$ and $\pm 1000 \mathrm{~s}^{-1}$ ), the experimental stress-strain curves (Figure 3) indicate that the strain hardening is low. The Ti6Al4V is therefore prone to unstable deformation which results in onset of necking at strains as low as 2 to 3 percent. In this material, necking does not lead to immediate failure. Between the moment of necking and fracture the Ti6Al4V shows a large potential for plastic strain. Just before fracture, localized necking typical for thin sheets occurs.

DIC is used to correct the experimentally obtained stress-strain curves and the result is also shown in Figure 3. By measurement of the local strain, the stress-strain curve beyond necking can be estimated. The strain, represented in the DIC-corrected curve on the figure, is the local logarithmic strain measured in the centre of the specimen. The strain between the twelve discrete data points, 
indicated by squares, is obtained by linear interpolation. The true axial stress in the corrected curve is deduced from the stress calculated from the Hopkinson waves with the conversion from engineering into true stress values based on the locally measured strain. In contrast with the uncorrected stressstrain curves, the DIC-corrected curve shows that there is strain-hardening up to more than $20 \%$ of strain. The maximal axial stress is approximately $15 \%$ higher than the yield stress. The difference between the curves directly measured by the Hopkinson bar records and the one corrected with the DIC data is huge. The apparent good correspondence of the curves for strains up to $10 \%$ is misleading.

Figure 4 shows that also for lower strains there exists a difference between the average and local strain, but it is rather difficult to see from the stress-strain curves of Figure 3 because of the low strain hardening. From this it can be concluded that, an optimization method for retrieving accurate stress-strain curves, which is solely based on comparing stress-strain curves will not be sufficient for a material with low strain hardening such as Ti6Al4V.

Analysis of the cross sectional reduction of the fractured specimens confirms the high strains that are measured with DIC. The cross sectional area is determined with a dial gauge and projection microscope. The average fracture strain out of 11 measurements on 6 specimens is $36 \%$ with a standard deviation of $7 \%$.

Figure 3: True stress-plastic axial strain curves obtained by Hopkinson bar records and DIC. Calculated values of true stress and plastic strain values after onset of necking are only displayed for comparison with the DIC results.

Figure 4: Comparison of the average strain measured from the Hopkinson bar records and local strain in the centre of the specimen measured by DIC 
Two important conclusions can be drawn from the local strain measurements on tensile specimens:

- The strain field is highly heterogeneous. From the onset of loading, the strain is not uniformly distributed in both the axial and transverse direction. The strain in the centre of the gage section is at least twice the strain near the transition zones in the beginning of the experiment and more than 5 times higher at the end of the experiment. As a consequence, the calculation of the true stress will yield an underestimation of the actual existing stress in the centre. In addition, the fracture strain is much higher than the one deduced from the uncorrected Hopkinson results.

- Non-axial stresses exist in the gage section. Transverse contraction of the material around the centre of the gage section is constrained by the surrounding material and non-axial tensile stresses arise. Thus, the axial stress and strain measured with the Hopkinson bar records are no more than two components of the triaxial stress and strain state in the specimen. The effective stress and strain relation necessary for constitutive modelling is not obtained. Therefore, even the DIC-corrected true axial stress-strain curve from Figure 3 cannot be used directly for material modelling.

\subsection{Shear test results}

Two series of dynamic shear experiments are performed with the axis of the specimen in the rolling direction (RD) and in the transverse direction (TD). The relative displacement speed of the bar ends' is approximately $3 \mathrm{~m} / \mathrm{s}$ and is nearly constant during the experiment. The average shear stress versus displacement curve of two typical experiments is shown on Figure 5. The shear stress is estimated by assuming a constant shear surface [21]. The shear strain is less obvious to determine from the Hopkinson signals. The logarithmic shear strain in the centre of the shear region, measured with DIC is given on a separate curve. 
Two parts can be easily distinguished in the curves. In the first part, until a displacement of approximately $0.2 \mathrm{~mm}$, the specimen mainly deforms elastically. The strain in the shear region is low with only some plastic deformation at the notches. In the second part, the material in the shear region starts to yield. Strain hardening can clearly be seen in the experimental curves. The maximal stress is approximately $15 \%$ higher than the yield stress. All experiments finish by an abrupt drop in the force. There is no necking before fracture in the shear tests but on the other hand microscopic observation of the shear fracture reveals the presence of an adiabatic shear band. There is no difference in the hardening behaviour between the RD and TD specimens but some effect of the material orientation is found in the displacement at fracture, which agrees with the tensile test results.

Figure 5: Shear stress-displacement curves and shear strain measured by DIC

\section{Material behaviour extraction}

\subsection{Finite element model}

A 2D finite element model of the two experiments is defined in ABAQUS/Explicit. Plane stress elements (CPS4R) are used. The tensile specimen has 6072 elements and the shear specimen has 8077 elements (Figure 6). Verification of the chosen mesh was done by performing tensile and shear test simulations with different mesh densities and 3D simulations. It is found that using a 2D instead of a 3D model does not affect the accuracy of the simulations significantly, even during diffuse necking, which could be expected regarding the low thickness of the specimens $(0.6 \mathrm{~mm})$. The displacement of the areas that are glued into the Hopkinson bar slots is constrained. A uniform velocity is imposed at one end of the specimen: after a rise time of $20 \mu \mathrm{s}$, the right side is moving at a constant velocity in the axial direction, corresponding with the velocity during the experiments. The other side of the specimen is completely fixed. 
For the material an elasto-plasticity model with isotropic hardening is used. Anisotropy has not been taken into account because the experimental results indicate that anisotropy has little effect on the dynamic strain hardening behaviour of the studied material (Figure 3 and Figure 5). The JohnsonCook (JC) model is used to describe the effect of the strain hardening, strain-rate $(\dot{\varepsilon})$ hardening and thermal softening on the stress $\sigma$ as a function of the plastic strain $\varepsilon_{p}$ :

$$
\sigma=\left(1+B \varepsilon_{p}^{n} f\left(1+C \ln \frac{\dot{\varepsilon}}{\dot{\varepsilon}_{0}}\right)\left(1-\left(\frac{T-T_{\text {room }}}{T_{\text {melt }}-T_{\text {room }}}\right)^{m}\right)\right.
$$

where $\dot{\varepsilon}_{0}$ is a reference value of the strain rate, $T$ the temperature, $T_{m e l t}$ the melting temperature and $T_{\text {room }}$ is the room temperature. $\mathrm{A}, \mathrm{B}, \mathrm{C}, \mathrm{n}$ and $\mathrm{m}$ are material parameters. The Johnson-Cook model was selected here because it is very often chosen for high strain rate material modelling because of its good prediction and simplicity [26]. Lee and Lin [27] showed that one set of JC parameters is sufficient to describe the behaviour of Ti6Al4V from room temperature up to $1100^{\circ} \mathrm{C}$ at high strain rates. Although, the parameters $\mathrm{A}, \mathrm{B}, \mathrm{C}, \mathrm{n}$ and $\mathrm{m}$ are related to physical characteristics of the material, it should be kept in mind that the model is phenomenological.

Heat is generated by the plastic deformation in the material. The resulting temperature increase for an adiabatic process can be estimated by integration of the energy dissipated by plastic work:

$$
\Delta T=\beta \frac{1}{\rho c} \int \sigma d \varepsilon
$$

where $\rho$ and $c$ are the mass density and specific heat of the material respectively. In the simulations, the specific heat $\mathrm{c}$ is assumed to be independent of the temperature. On the one hand, recent works by Rosakis [28] and Longere [29] show that the Taylor-Quinney coefficient $\beta$ is not constant during deformation. On the other hand, Kapoor and Nemat-Nasser [30] have shown that infra-red detectors typically underestimate the temperature rise and that for most materials the assumption that all the work done is converted into heat is valid. Walley at al. [31] indicate that uncertainty on radiation 
emissivity affect IR measurement accuracy. For this study, the Taylor-Quinney coefficient $\beta$ is assumed to have a constant value of 0.9 . This is considered to be an acceptable approximation in the scope of this study because of the rather modest temperature increase. Table 1 summarizes the values of the material model used. The parameters A, B, C, n and $\mathrm{m}$ are determined in $\S 3.2$.

Table 1: Material parameters used for Ti-6Al-4V in all simulations

Figure 6: Mesh in the gauge region of the tensile and shear specimen

\subsection{Obtaining the local material behaviour for Ti6Al4V}

The local stress, strain, strain rate and temperature are calculated by combining the experimental and simulated results. On the one hand, the experiments provide the global force-displacement behaviour of the specimen. On the other hand, the simulations give the relation between the global force and local stress and between the displacement and local strain in the centre of the specimen in function of the specimen elongation. This relation is highly dependent on the structural specimen and material behaviour and thus on the material model parameters used in the FE model. Because the material behaviour and model parameters describing it are the unknowns in our problem, an iterative process is necessary. Tables 2, 3 and 4 present the JC material model parameters for Ti6Al4V, obtained and used during the process. The parameters $\mathrm{m}$ and $\mathrm{C}$ are adapted during successive iterations (Table 3 ) while the parameters $A=\sigma_{y}, B$ and $n$ are determined only once using a static tensile test (Table 4) at a strain rate of $8 \cdot 10^{-5} \mathrm{~s}^{-1}$. This low strain rate is necessary to ensure isothermal conditions.

The names of the parameter sets indicate the type and iteration number of the experiment from which the material behaviour is extracted and are in the format Set[number of iteration][T=fitted to tensile experiment, $S=$ fitted to shear experiment]. Figure 7 illustrates how the material behaviour is extracted from the tensile and/or shear tests and the procedure is described hereunder. 
Step 1: A dynamic experiment is carried out. For a tensile test, a first estimation of the material behaviour could be obtained using the classic assumptions of a homogeneous and uni-axial stress and strain distribution (parameter Set1T, Table 4). Estimation of the material behaviour from the shear test is less obvious because the relation between the measured elongation of the specimen and the strain is not well known due to the complex strain distribution in the specimen. Two tensile and two shear tests are used in the next steps.

Step 2: FE simulations of the dynamic experiments are performed. The material model parameters used in this simulation can be based on the results of "Step1" or can come from literature or preceding iteration steps. For the first iteration, the first option is the most convenient for tensile tests but difficult to apply for the shear test and other non-standard tests. Therefore and to test the general applicability of the procedure, the material model parameters used in this work come from dynamic compression tests described in literature (Model parameters "SetI, Table 2, [32]).

The following important relationships are deduced from the simulations:

A. The ratio of the total force $\mathrm{F}$ and local effective stress $\sigma$ in the centre of the specimen as function of the total specimen elongation $\Delta \mathrm{u}(\mathbf{A 1})$. For the tensile tests and shear tests, the value of this ratio is close to respectively the cross section of the specimen and the cross section of the specimen multiplied by $\sqrt{3}$. Its exact value depends not only on the specimen geometry and material behaviour but also on the cross sectional area reduction of the specimen, stress triaxiality, and stress distribution.

B. The ratio of the total elongation $\Delta \mathrm{u}$ and local effective strain $\varepsilon$ in the centre of the specimen as function of the total specimen elongation $\Delta u($ B1). This value also depends on the specimen geometry and material behaviour.

C. The local temperature and strain rate as function of the total specimen elongation $\Delta \mathrm{u}(\mathbf{C 1})$. The local temperature and strain rate are typically higher than the temperature and strain rate calculated from the Hopkinson measurements.

14 
Step 3: Relationship A from "Step 2" is used to estimate the local stress in the centre of the specimen, based on the experimentally measured force. Relationship B is used for estimating the local strain, based on the experimentally measured elongation. The accuracy of the extracted material behaviour is of course dependent on the accuracy of the simulation, which is checked in $\S 4.2$. It is furthermore important that the calculation of the total elongation $\Delta \mathrm{u}$ from the Hopkinson bar waves is done accurately, because the correlation of the experimental and simulated data is based on $\Delta \mathrm{u}$ (see relation $\mathbf{A}, \mathbf{B}$ and $\mathbf{C}$ ). In this work, the accuracy of the experimental $\Delta \mathrm{u}$ is improved by a correction equal to the difference in simulated and experimentally measured displacement $\Delta \mathrm{u}$ at the yield point.

Step 4: New material model parameters are calculated to the obtained local effective stress-strain curves and local temperature and strain rate data from "Step3" (Table 4). Determination of the model parameters can be done with only the tensile tests $(\operatorname{Set} 2 T)$, only the shear tests $(\operatorname{Set} 2 S)$ or both types of tests as presented on Figure 7 (Set2TS). Here, a least square method is used for the fitting.

Step 5: New simulations are performed with the material model parameters calculated in the previous step. The simulation results are then compared with the experimental results. A second iteration can be done if the results are not satisfactory. The relations A2, B2 and C2 provided from the second simulation are more realistic than A1, B1 and $\mathbf{C 1}$ because the model Set $2 x$, used in this simulation is more realistic than Set1.

Steps 2, 3 and 4 are repeated until sufficient agreement between the experiments and simulations is obtained and the model parameters converge. The experimental force-displacement curves or local strain measurements can be compared with simulation results.

Figure 7: Schematic presentation of procedure to extract material behaviour and fit material model parameters from experiments by iterative simulation process 
Table 2: Initial JC parameters obtained from dynamic compression tests on an extruded bar of Ti-6Al-4V

Table 3: Parameters A, B and $\mathrm{n}$ fitted to quasi-static tensile results

Table 4: Parameters $\mathrm{C}$ and $\mathrm{m}$ for subsequent optimization steps

Figure 8 shows the local effective stress-effective plastic strain curves extracted from the experimental results after four iterations. The strain hardening and maximum strain presented on these corrected curves is clearly higher than presented on Figure 2 and corresponds better with the DIC and post-mortem measurements. Even beyond diffuse necking, the Ti6Al4V shows some strain hardening on the effective stress-strain curves up to strains of $20 \%$, which could definitely not be seen on the uncorrected stress-strain curves. The softening that occurs at strains higher than $20 \%$ is due to damage. In contrast with the experimental force-displacement curves, the effective stresseffective plastic strain curves calculated from tensile tests can now be compared with those from shear tests. As a result, using this material behaviour extraction technique, the shear test can be used for characterizing the constitutive material behaviour. It is seen that the Ti6Al4V shows more strain hardening in shear than in tension but on the other hand the fracture strain is lower in shear than in tension.

Figure 8: Experimental local effective stress-effective strain curves for two tensile and shear tests. The FE simulations used to extract these curves are based on parameter set "Set4T" for tensile test simulation and "Set $4 \mathrm{~S}$ " for the shear simulation. Oscillations in these curves are attributed to the experimental measurements rather than the extraction technique itself. 


\section{Discussion}

\subsection{Evaluation of the extracted material behaviour and model}

Evaluation of the extracted material behaviour and the corresponding material model is done by comparing the simulated and experimental force-displacement curves. Figure 9 shows two tensile curves from experiments and 4 curves from simulations. Firstly, the tensile experiment is simulated with the JC parameters retrieved in the direct way $(\operatorname{Set} 1 T)$ : the model is deduced from the experimentally measured average stress-strain curves. This model results in a not converging simulation because the material behaviour is unstable due to the overestimated thermal softening. Secondly, the simulation result with the JC parameters from literature $($ SetI $=$ initial model $)$ is not very good either, but is more realistic because the fast strain localization does not arise. Thirdly, Figure 9 shows the results from the tensile simulations with the material model calculated by the experimental-numerical method at different iteration steps. It is clear that the simulations with these corrected models agree very well with the experiments. Even the onset of heavy strain localization at a displacement of approximately $0.8 \mathrm{~mm}$ is predicted without the use of a damage model. However, it should be kept in mind that the experimental strain distribution just before fracture differs from sample to sample. In this final stage, the simulated strain distribution will not necessarily correspond with the experimental one. Advanced fracture mechanics would be necessary to reduce this uncertainty. There is a very large improvement between the simulation with the initial model and the second model $(\operatorname{Set} 2 T)$. There is no need to do a lot of iterations because the result after two or three iterations (Set3T and Set4T) is already very good which indicates fast convergence of the extracted material behaviour and the corresponding model.

To assess the suitability of tensile and shear experiments for material modelling purposes, the material behaviour has been determined in three different ways: using only the tensile test results (left side of Figure 7), using only the shear test results (right side of Figure 7) and using both test 17 
types. The simulated and experimental force-displacement curves from tensile and shear tests are compared in Figure 10 and 11. As discussed before, tensile simulations with material model parameters deduced from tensile tests gives very accurate results (Set4T). On the other hand, simulation of the tensile test with the parameter set fitted on the shear experiments (Set4S) does not give satisfactory results. The opposite is found for simulation of the shear test, as illustrated on Figure 11. The best simulation of a shear experiment is done with JC parameters determined from the shear experiments $(\operatorname{Set} 4 S)$ while the parameters determined from the tensile experiments $(\operatorname{Set} 4 T)$ do not give the same good results for shear simulations.

It can be concluded that the material model based on the extracted material behaviour from tensile tests or shear tests is appropriate for the simulation of respectively a tensile or shear experiment but not for both and thus that different material models are needed to describe the material behaviour for different loading cases. For a more complex loading case, a model that performs well for both tensile and shear deformation simultaneously is desired. Such model can be found by combining the shear and tensile experiments in the model parameter identification process (left and right side of Figure 7). Furthermore, it is better to distinguish the material behaviour from the global specimen response when the two test types are combined because the structural behaviour of the two specimen geometries is totally different but the material behaviour is almost the same. The JC model with parameter sets Set4TS is a compromise between accuracy and general applicability of the model. Figure 10 and 11 demonstrate that these models give quite good results for both loading cases.

Figure 9: Comparison of experimental and simulated average stress - displacement tensile curves.

Figure 10: Comparison of experimental and simulated force-displacement tensile test curves after $4^{\text {th }}$ iteration

Figure 11: Comparison of experimental and simulated force-displacement shear test curves after the $4^{\text {th }}$ iteration 


\subsection{Validation of the numerical model and extraction technique}

Comparison of the experimental and simulated force-displacement curves ( $\$ 4.2)$ is a straightforward way to check the performance of the material model but is not sufficient for sound validation. Indeed, although the simulated force-displacement curves correspond with the experimental ones, simulated local stress and strain values do not necessarily match with the experiments. It needs to be verified if the FE model, including the material model, was a good choice for modelling the specimen behaviour. Different methods are used to assess the local strain distribution in the specimen.

\subsubsection{Digital image correlation}

The digital image correlation (DIC) technique described in section 2.1 is used to obtain the experimental strain distribution. However, when comparing the experimental distribution with the simulated one, prudence is called for. Although the DIC is called a local measurement technique, the strain in a single point is not obtained. Indeed, the strain is actually calculated from the average displacement of several neighbouring subsets of pixels, typically containing 5 to 15 pixels. Consequently, the strain at the edges cannot be determined. In a similar way, the strain obtained with FEM is dependent on the mesh size, certainly when strong localization occurs.

Figure 12 shows that the simulated and the corresponding measured strain distribution in a tensile specimen match quite well. The assumption of homogeneous strain distribution is clearly not fulfilled: the strain is inhomogeneous along both the axial and transverse direction of the specimen. The simulated and experimental strain distributions in the shear specimen are compared in Figure 13. It is seen that the width of the shear region and the maximal obtained shear strain correspond very well. The results justify the use of the numerical results for material behaviour extraction during the shear test. 
Figure 12: Comparison of the simulated (Set4T) and DIC measured axial strain distribution. The average strain measured with the Hopkinson waves is $13.5 \%$ at the moment of these images. Some parts of the gage section are not visible because of the black glue, used to fix the specimen to the bars, soiling the specimen's surface.

Figure 13: Comparison of the simulated (Set4S) and measured shear strain distribution after a displacement of $0.66 \mathrm{~mm}$.

\subsubsection{Transverse contraction of the specimen}

In addition to the DIC strain field, the transverse contraction of the tensile specimen is used for a more straightforward model validation. The transverse contraction is not only measured post mortem, but also during the dynamic experiment using images from the high speed camera. An algorithm written in Matlab $^{\odot}$ is used to detect the edges of the specimen on the images from the high speed camera. In Figure 15 the simulated and measured transverse contraction of the specimen is represented. As can be seen, the simulated and measured width profiles along the specimen agree well, which is a further validation of the simulation.

Figure 14: Transverse contraction of the specimen, just before fracture. The shaded region in the plot area is a rescaled image of the specimen.

\section{Conclusion}

Experiments show that the strain hardening of Ti6Al4V is low and very soon after the onset of plastic deformation in a tensile experiment, the strain tends to localize around the centre of the gage section of the specimen. Consequently, the traditional assumption of a homogeneous stress and strain distribution is not valid anymore and no unambiguous relation exists between the measured specimen force and elongation and respectively stress and strain in the specimen. For shear 
experiments, the strain distribution in the shear region is even less homogeneous; the material behaviour cannot be calculated directly from these experiments.

A combined experimental-numerical method to allow the extraction of the material behaviour from dynamic tensile and shear experiments is presented. On the one hand, the experiments provide the global force-displacement behaviour of the specimen. On the other hand, the simulations give the relation between the global force and displacement and the local stress and strain. The Johnson-Cook model is used in the FEM to describe the material behaviour. The parameters of that model are deduced from the experimental results by use of the simulated strain distribution itself. Therefore an iterative procedure is worked out to retrieve these parameters. This simple approach is applicable for different specimen geometries where non-homogeneous stress and strains exist. By this method, the shear test is made appropriate for characterizing the constitutive material behaviour and the tensile test can be used to characterize the material behaviour at large strains.

It is found that the Ti6Al4V exhibits more strain hardening in shear than in tensile while the fracture strain in shear is lower than in tensile loading. Further, it is found that the material model deduced from the results of the tensile and shear experiments simultaneously is more general applicable than a model that is solely determined on tensile or shear experiment results.

The performance of the method to extract the material behaviour and to calculate the appropriate material model parameters is assessed in three different ways. Firstly, the simulated and experimental force-displacement curves are compared. Secondly, digital image correlation is used to evaluate the simulated strain distribution in the tensile and shear specimen. A last validation method measures the reduction of the specimen's cross section to estimate the strain distribution along the gage length. The three methods find a satisfactory agreement between experiments and simulations. 


\section{Acknowledgements}

The authors would like to acknowledge The Interuniversity Attraction Poles Program (IUAP) of the Federal Science Policy of Belgium and the partners of IUAP-VI (www.m3phys.be). The authors acknowledge the technical support of Dr. P. Lava and Dr. D. Debruyne from the Catholic University College Ghent for use of their in-house developed image correlation software MatchID.

\section{References}

[1] Verleysen P, Degrieck J, Experimental investigation of the deformation of Hopkinson bar specimens, Int J Impact Eng, 30, 3 (2004) 239-53

[2] Gilat A, Schmidt TE, Walker AL, Full Field Strain Measurement in Compression and Tensile Split Hopkinson Bar Experiments, Exp Mech, 49, 2 (2009) 291-302

[3] Verleysen P, Degrieck J, Verstraete T, Van Slycken J, Influence of specimen geometry on split Hopkinson tensile bar tests on sheet materials, Exp Mech, 48, 5 (2008) 587-98

[4] Bronkhorst CA, Cerreta EK, Xue Q, Maudlin PJ, Mason TA, Gray GT, An experimental and numerical study of the localization behavior of tantalum and stainless steel, Int J Plasticity, 22, 7 (2006) 1304-35

[5] Gilat A, Cheng CS, Modeling torsional split Hopkinson bar tests at strain rates above 10,000 s(-1), Int J Plasticity, 18, 5-6 (2002) 787-99

[6] Verleysen P, Verhegghe B, Verstraete T, Degrieck J, Numerical study of the influence of the specimen geometry on split Hopkinson bar tensile test results, Latin American Journal of Solids and Structures, 6, 3 (2009) 285-98

[7] Rusinek A, Klepaczko JR, Shear testing of a sheet steel at wide range of strain rates and a constitutive relation with strain-rate and temperature dependence of the flow stress, Int J Plasticity, 17, 1 (2001) 87-115

[8] Dorogoy A, Rittel D, Numerical validation of the shear compression specimen. Part II: Dynamic large strain testing, Exp Mech, 45, 2 (2005) 178-85

[9] Bridgman PW, Studies in large plastic flow and fracture: with special emphasis on the effects of hydrostatic pressure, McGraw-Hill, 1952.

[10] Zhang ZL, Hauge M, Odegard J, Thaulow C, Determining material true stress-strain curve from tensile specimens with rectangular cross-section, International Journal of Solids and Structures, 36, 23 (1999) 3497-516

[11] Zhang KS, Li ZH, Numerical-analysis of the stress-strain curve and fracture initiation for ductile material, Eng. Fract. Mech., 49, 2 (1994) 235-41

[12] Joun M, Eorn JG, Lee MC, A new method for acquiring true stress-strain curves over a large range of strains using a tensile test and finite element method, Mechanics of Materials, 40, 7 (2008) 586-93

[13] Kajberg J, Sundin KG, Melin LG, Ståhle P, High strain-rate tensile testing and viscoplastic parameter identification using microscopic high-speed photography, Int J Plasticity, 20, 4-5 561-75

[14] Avril S, Bonnet M, Bretelle AS, Grediac M, Hild F, Ienny P, Latourte F, Lemosse D, Pagano S, Pagnacco E, Pierron F, Overview of identification methods of mechanical parameters based on fullfield measurements, Exp Mech, 48, 4 (2008) 381-402

[15] Hong T, Nian Z, Wei T, An iterative procedure for determining effective stress-strain curves of sheet metals, Int. J. Mech. Mater. Des., 5, 1 (2009) 13-27 
[16] Kajberg J, Lindkvist G, Characterisation of materials subjected to large strains by inverse modelling based on in-plane displacement fields, International Journal of Solids and Structures, 41, 13 (2004) 3439-59

[17] Kajberg J, Wikman B, Viscoplastic parameter estimation by high strain-rate experiments and inverse modelling - Speckle measurements and high-speed photography, International Journal of Solids and Structures, 44, 1 (2007) 145-64

[18] Lava P, Cooreman S, Coppieters S, De Strycker M, Debruyne D, Assessment of measuring errors in DIC using deformation fields generated by plastic FEA, Optics and Lasers in Engineering, 47, 7-8 (2009) 747-53

[19] Lava P, Cooreman S, Debruyne D, Study of systematic errors in strain fields obtained via DIC using heterogeneous deformation generated by plastic FEA, Optics and Lasers in Engineering, 48, 4 (2010) 457-68

[20] Picu RC, Majorell A, Mechanical behavior of Ti-6Al-4V at high and moderate temperatures - Part II: constitutive modeling, Materials Science and Engineering a-Structural Materials Properties Microstructure and Processing, 326, 2 (2002) 306-16

[21] Peirs J, Verleysen P, Van Paepegem W, Degrieck J, Novel pure-shear sheet specimen geometry for dynamic material characterisation, Dymat 2009: 9th International Conference on the Mechanical and Physical Behaviour of Materials under Dynamic Loading, Vol 1/2, (2009) 35-41

[22] Tarigopula V, Hopperstad OS, Langseth M, Clausen AH, Hild F, Lademo OG, Eriksson M, A study of large plastic deformations in dual phase steel using digital image correlation and FE analysis, Exp Mech, 48, 2 (2008) 181-96

[23] Kolsky H, An investigation of the mechanical properties of materials at very high rates of loading, Proc. Phys. Soc. Lond. B, 62, (1949) 676-700

[24] Mohr D, Gary G, Lundberg B, Evaluation of stress-strain curve estimates in dynamic experiments, Int J Impact Eng, 37, 2 (2010) 161-69

[25] Yang LM, Shim VPW, An analysis of stress uniformity in split Hopkinson bar test specimens, Int J Impact Eng, 31, 2 (2005) 129-50

[26] Dey S, Borvik T, Hopperstad OS, Langseth M, On the influence of constitutive relation in projectile impact of steel plates, Int J Impact Eng, 34, 3 (2007) 464-86

[27] Lee WS, Lin CF, Plastic deformation and fracture behaviour of Ti-6Al-4V alloy loaded with high strain rate under various temperatures, Materials Science and Engineering a-Structural Materials Properties Microstructure and Processing, 241, 1-2 (1998) 48-59

[28] Rosakis P, Rosakis AJ, Ravichandran G, Hodowany J, A thermodynamic internal variable model for the partition of plastic work into heat and stored energy in metals, Journal of the Mechanics and Physics of Solids, 48, 3 (2000) 581-607

[29] Longere P, Dragon A, Evaluation of the inelastic heat fraction in the context of microstructuresupported dynamic plasticity modelling, Int J Impact Eng, 35, 9 (2008) 992-99

[30] Kapoor R, Nemat-Nasser S, Determination of temperature rise during high strain rate deformation, Mechanics of Materials, 27, 1 (1998) 1-12

[31] Walley SM, Proud WG, Rae PJ, Field JE, Comparison of two methods of measuring the rapid temperature rises in split Hopkinson bar specimens, Review of Scientific Instruments, 71, 4 (2000) 1766-71

[32] Coghe F, Rabet L, Kestens L, Deformation mechanism of a commercial titanium alloy Ti6Al4V as a function of strain rate and initial texture, J. Phys. IV, 134, (2006) 845-50 
Table 1: Material parameters used for Ti-6Al-4V in all simulations

\begin{tabular}{|l|l|l|l|l|l|l|}
\hline$\rho\left(\mathrm{kg} / \mathrm{m}^{3}\right)$ & $\mathrm{E}(\mathrm{GPa})$ & $\mathrm{v}$ & $T_{\text {melt }}\left({ }^{\circ} \mathrm{C}\right)$ & $T_{\text {room }}\left({ }^{\circ} \mathrm{C}\right)$ & $c(\mathrm{~J} / \mathrm{kg} \mathrm{K})$ & $\beta$ \\
\hline 4428 & 116 & 0.33 & 1653 & 22 & 580 & 0.9 \\
\hline
\end{tabular}

Table 2: Initial JC parameters obtained from dynamic compression tests on an extruded bar of Ti-6Al-4V

\begin{tabular}{|l|c|c|c|c|c|c|}
\hline Setl & $\mathrm{A}=1120 \mathrm{MPa}$ & $\mathrm{B}=667 \mathrm{MPa}$ & $\mathrm{n}=0.47$ & $\mathrm{C}=0.027$ & $\mathrm{~m}=1.33$ & $\dot{\varepsilon}_{0}=1 \mathrm{~s}^{-1}$ \\
\hline
\end{tabular}

Table 3: Parameters A, B and n fitted to quasi-static tensile results

\begin{tabular}{|l|l|l|l|}
\hline $\mathrm{A}=951 \mathrm{MPa}$ & $\mathrm{B}=892 \mathrm{MPa}$ & $\mathrm{n}=0.70$ & $\dot{\varepsilon}_{0}=0.00008 \mathrm{~s}^{-1}$ \\
\hline
\end{tabular}

Table 4: Parameters $\mathrm{C}$ and $\mathrm{m}$ for subsequent optimization steps

\begin{tabular}{|l|c|c|c|c|c|c|}
\hline From & \multicolumn{2}{|r|}{ tensile test (T) } & \multicolumn{2}{r|}{ Shear test (S) } & \multicolumn{2}{r|}{ Tensile + shear test (TS) } \\
\hline & $\mathrm{C}$ & $\mathrm{m}$ & $\mathrm{C}$ & $\mathrm{m}$ & $\mathrm{C}$ & $\mathrm{m}$ \\
\hline Set1T & 0.020 & 0.55 & - & - & - & - \\
\hline Set2X & 0.019 & 0.59 & 0.018 & 0.76 & 0.018 & 0.66 \\
\hline Set3X & 0.016 & 0.66 & 0.013 & 0.83 & 0.015 & 0.70 \\
\hline Set4X & 0.017 & 0.62 & 0.013 & 0.84 & $\mathbf{0 . 0 1 5}$ & $\mathbf{0 . 7 1}$ \\
\hline
\end{tabular}




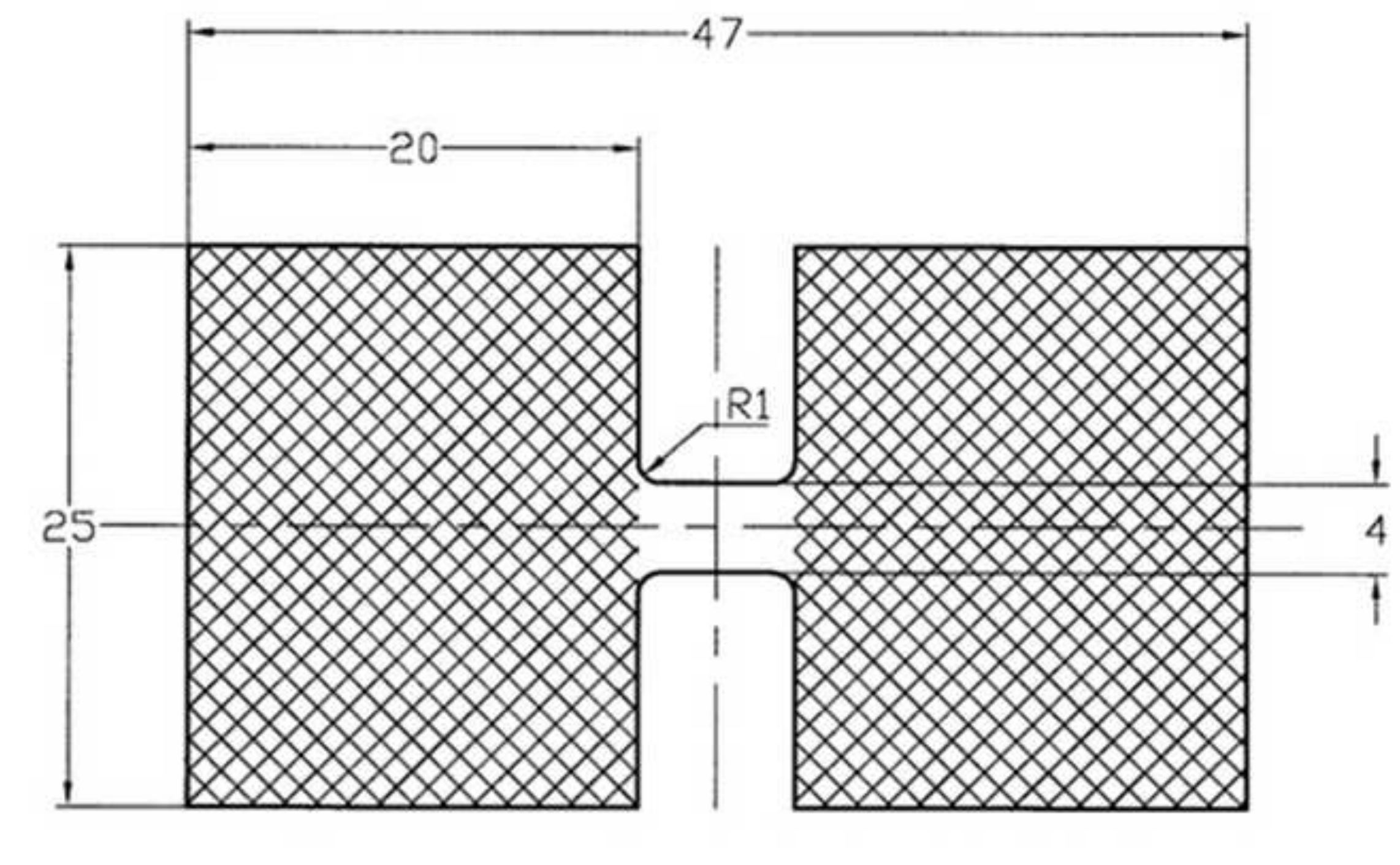

.

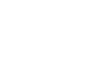

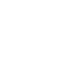


Figure2

Click here to download high resolution image

Test force

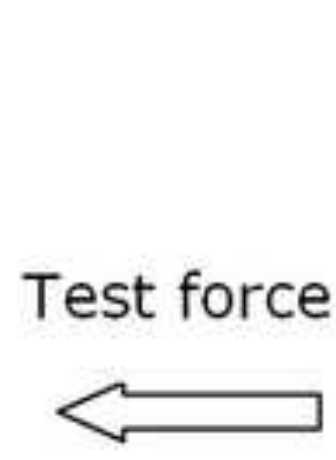

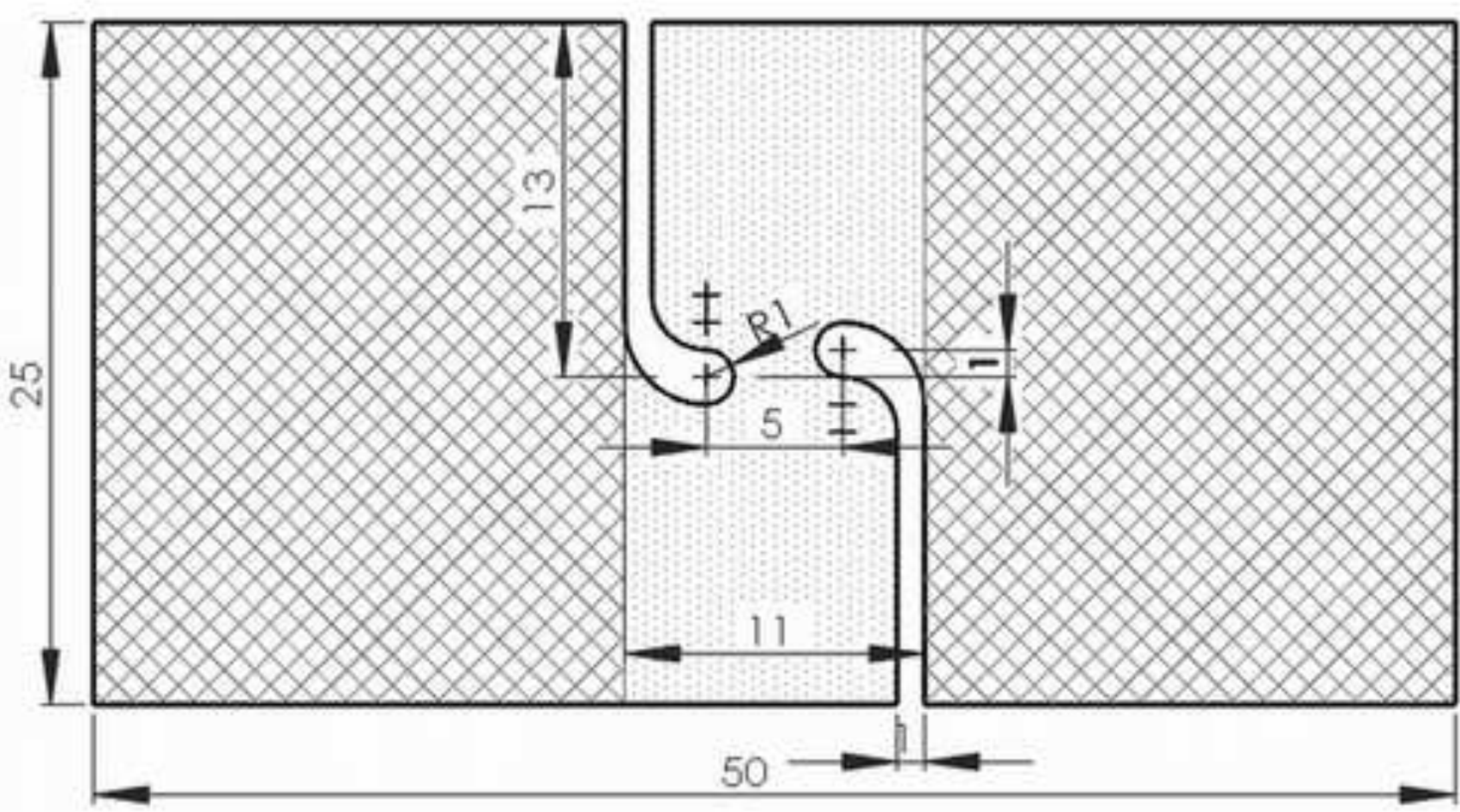

Test force

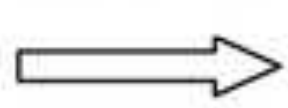

$\uparrow 2$
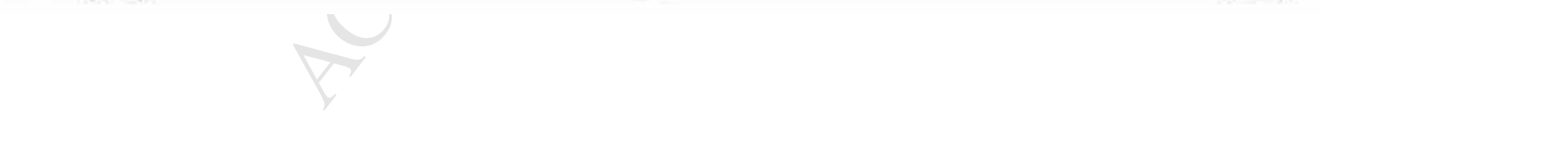


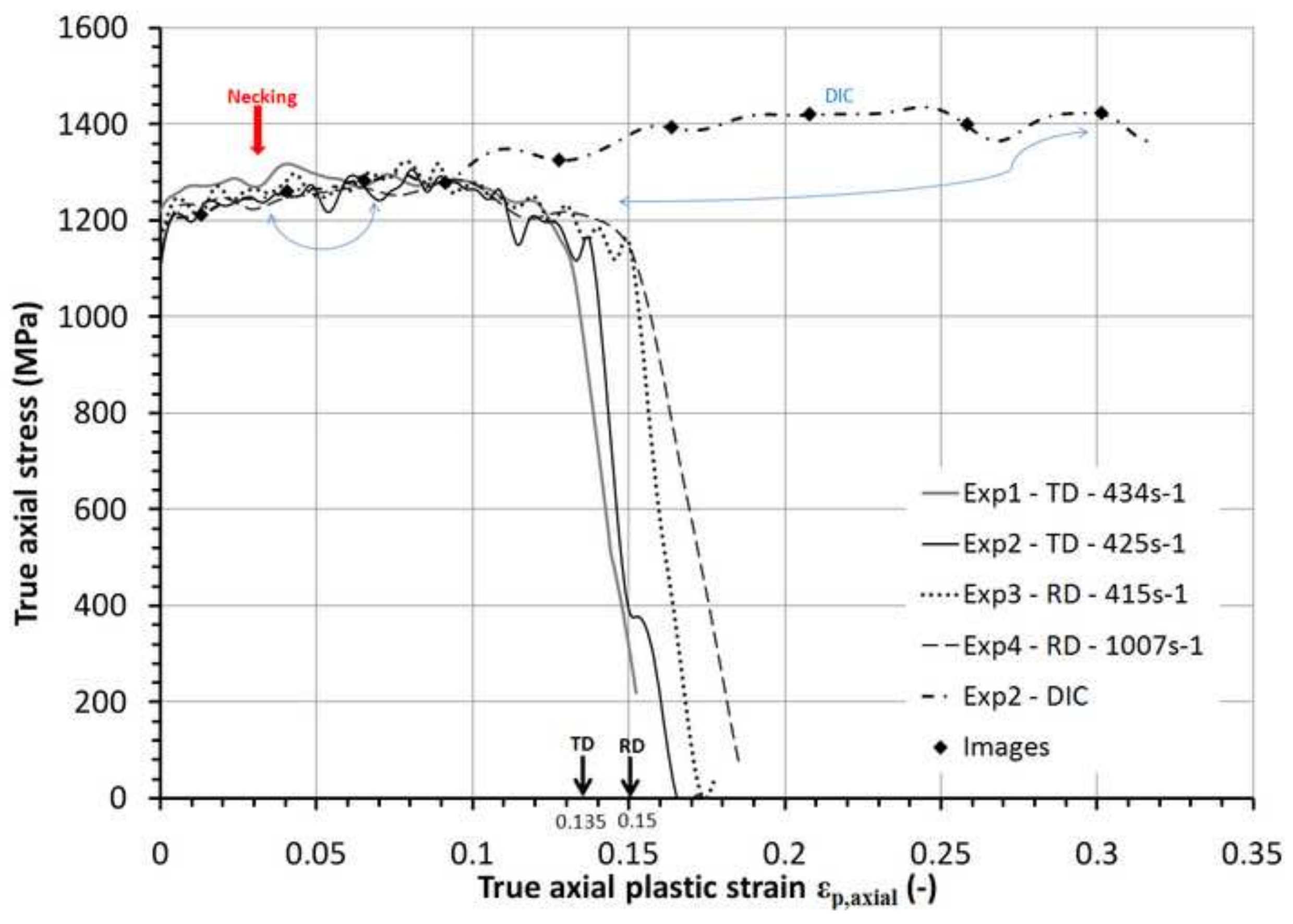




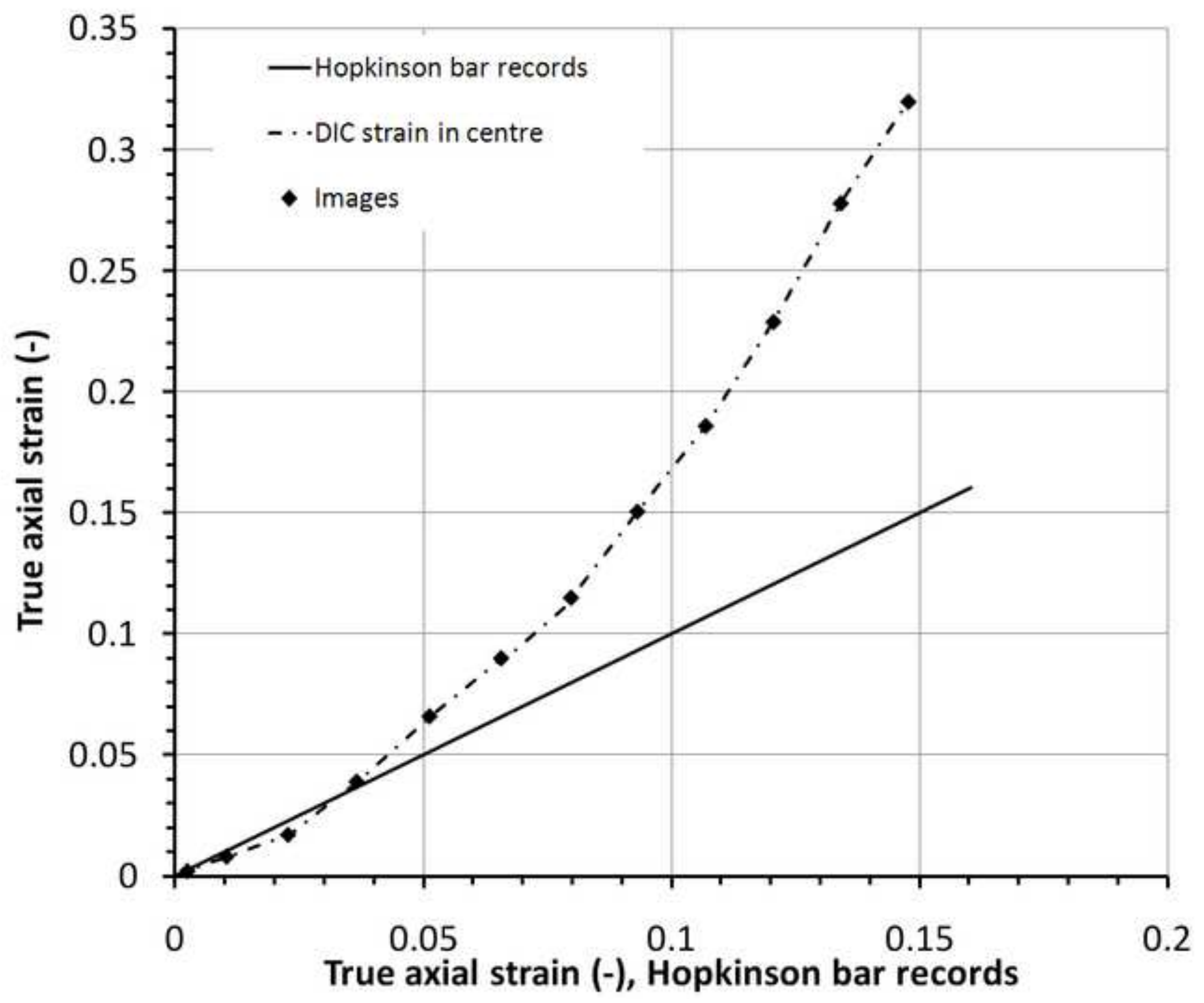




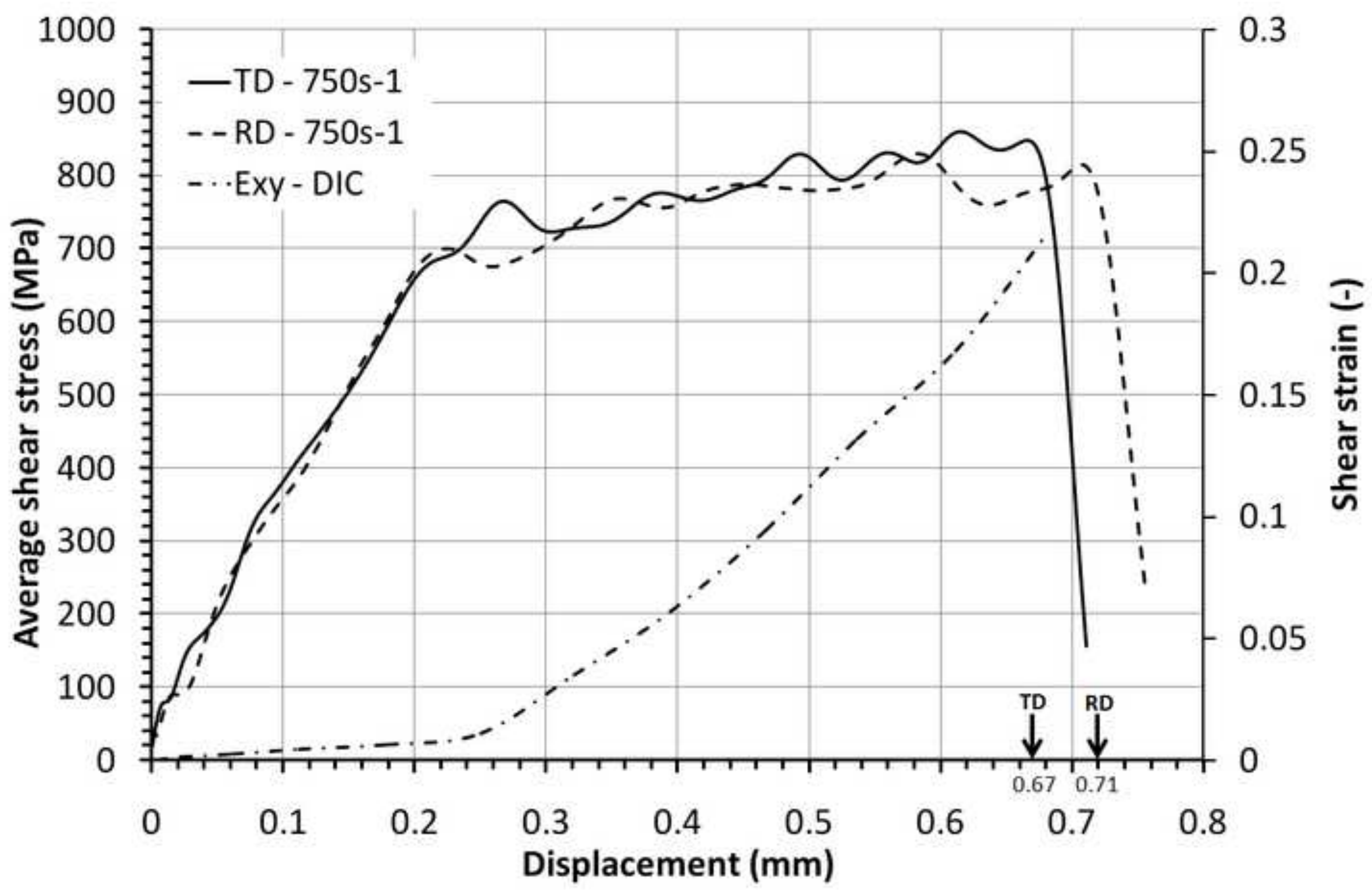


Click here to download high resolution image
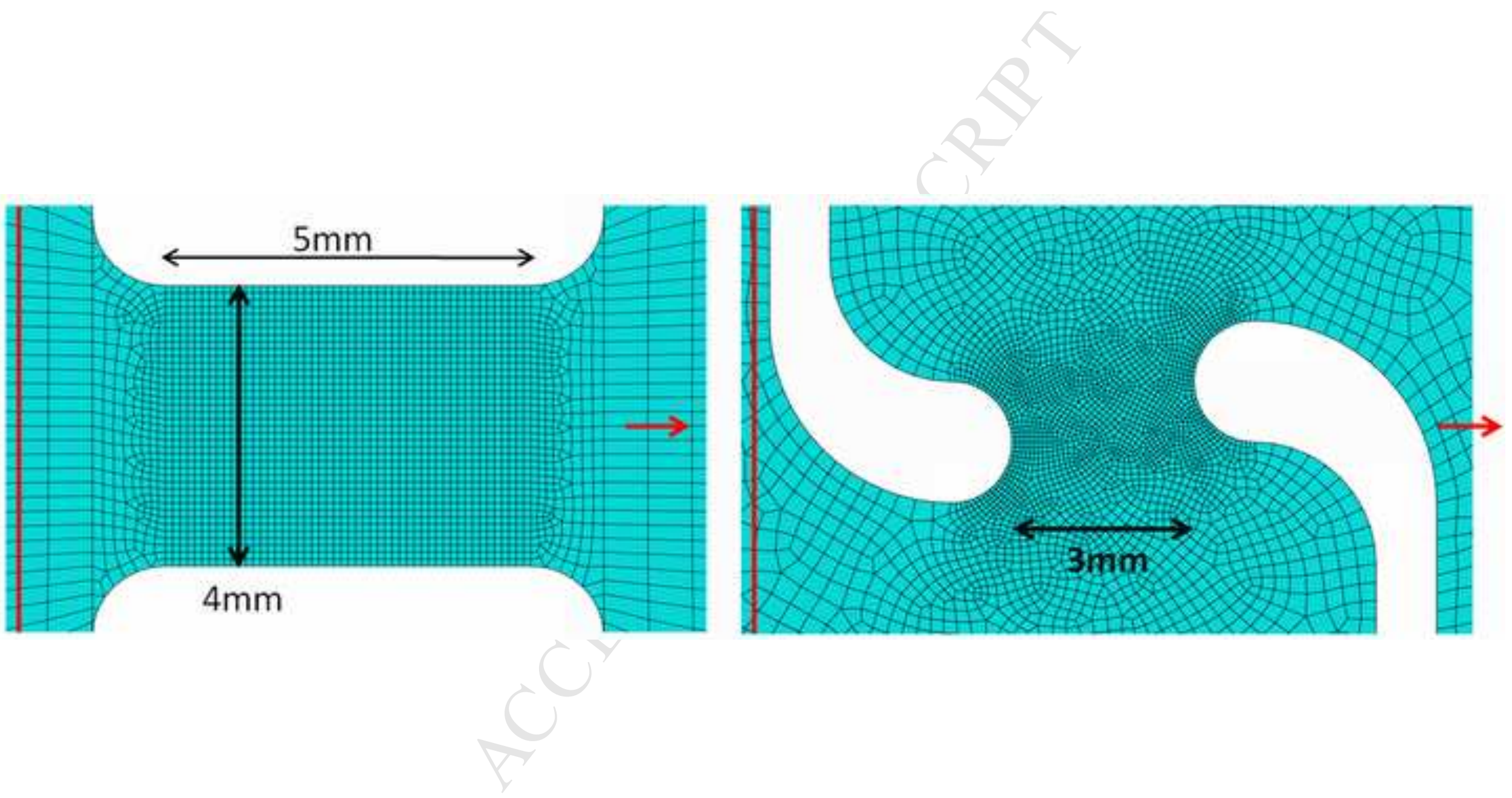


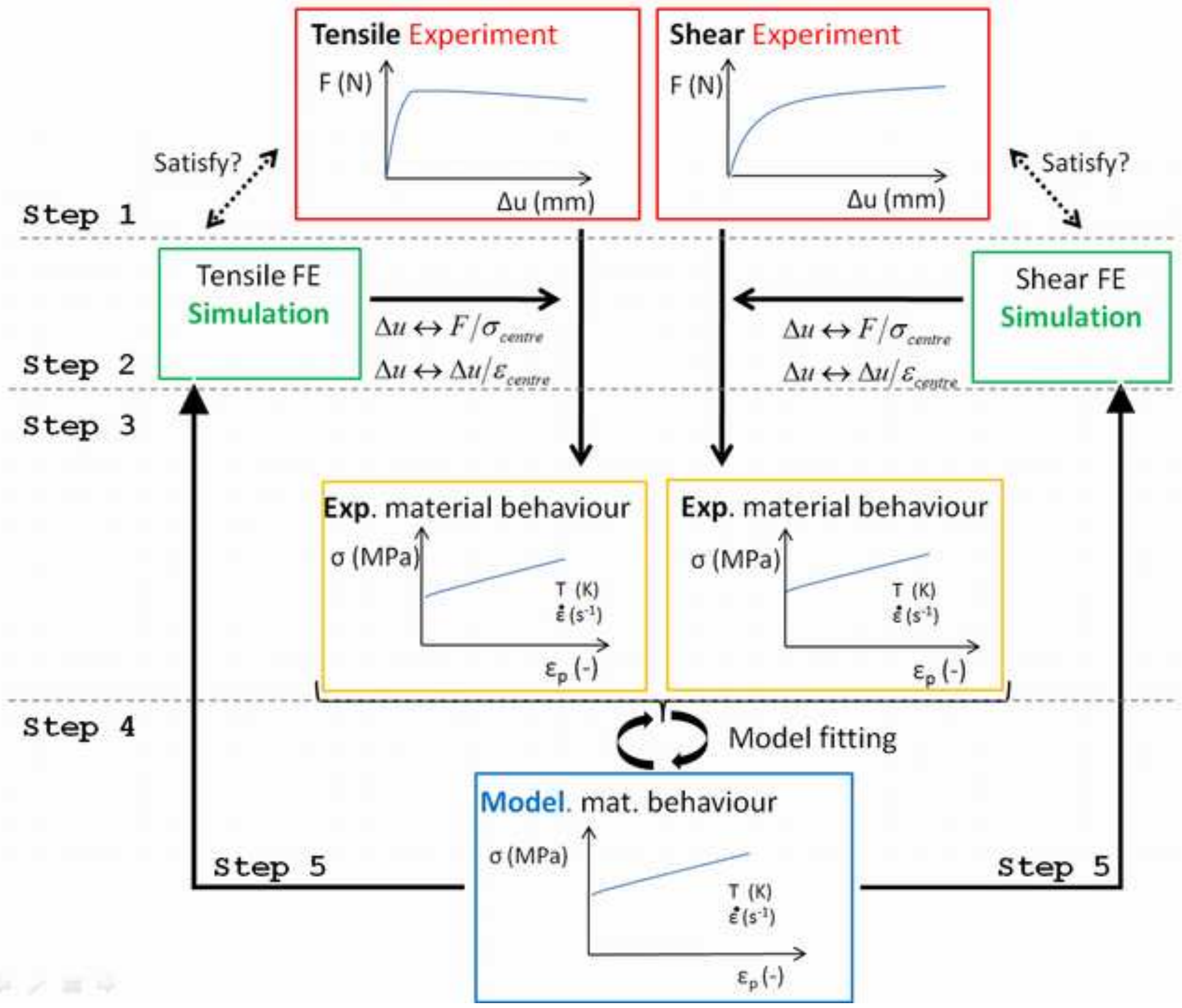




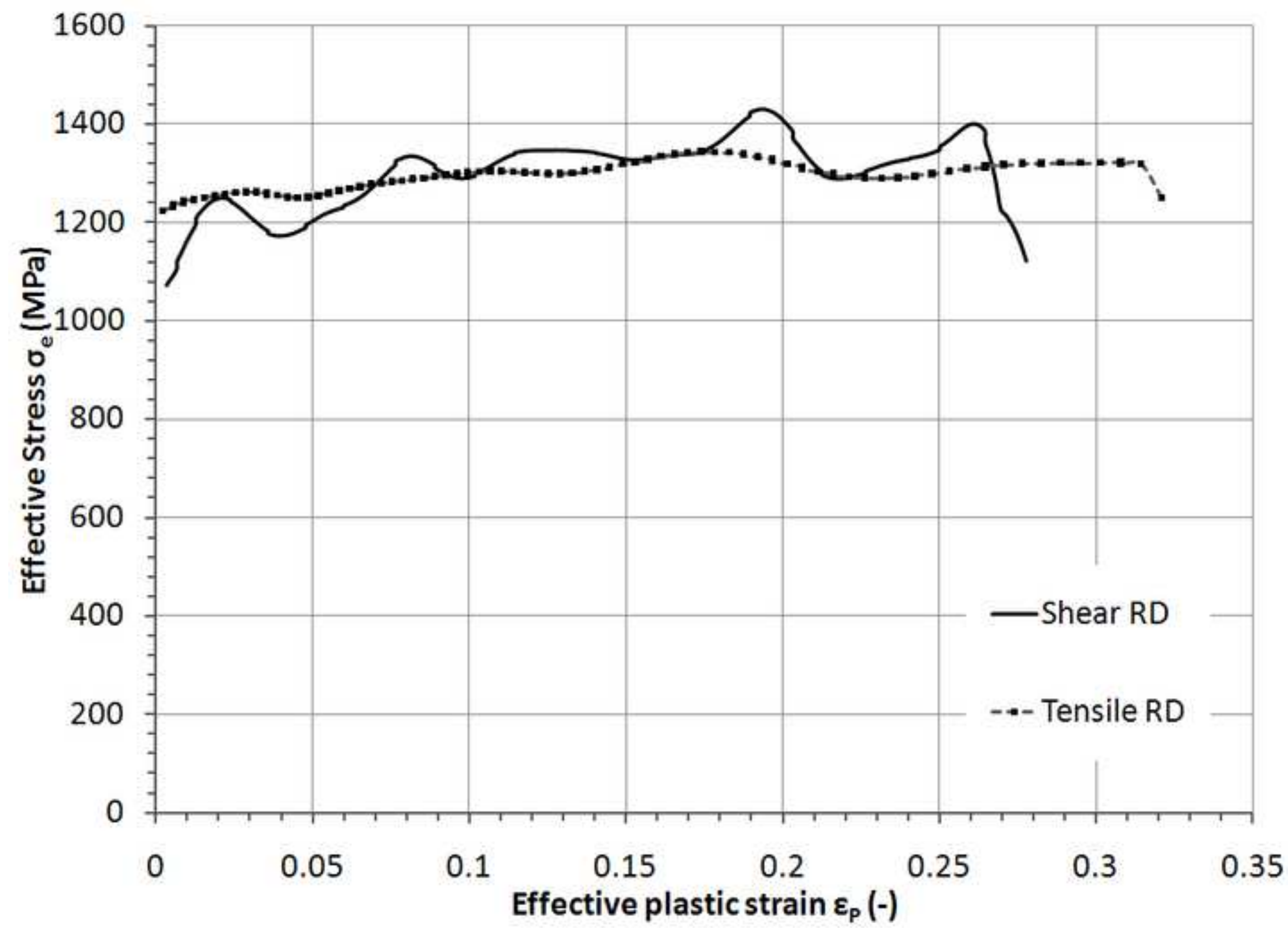




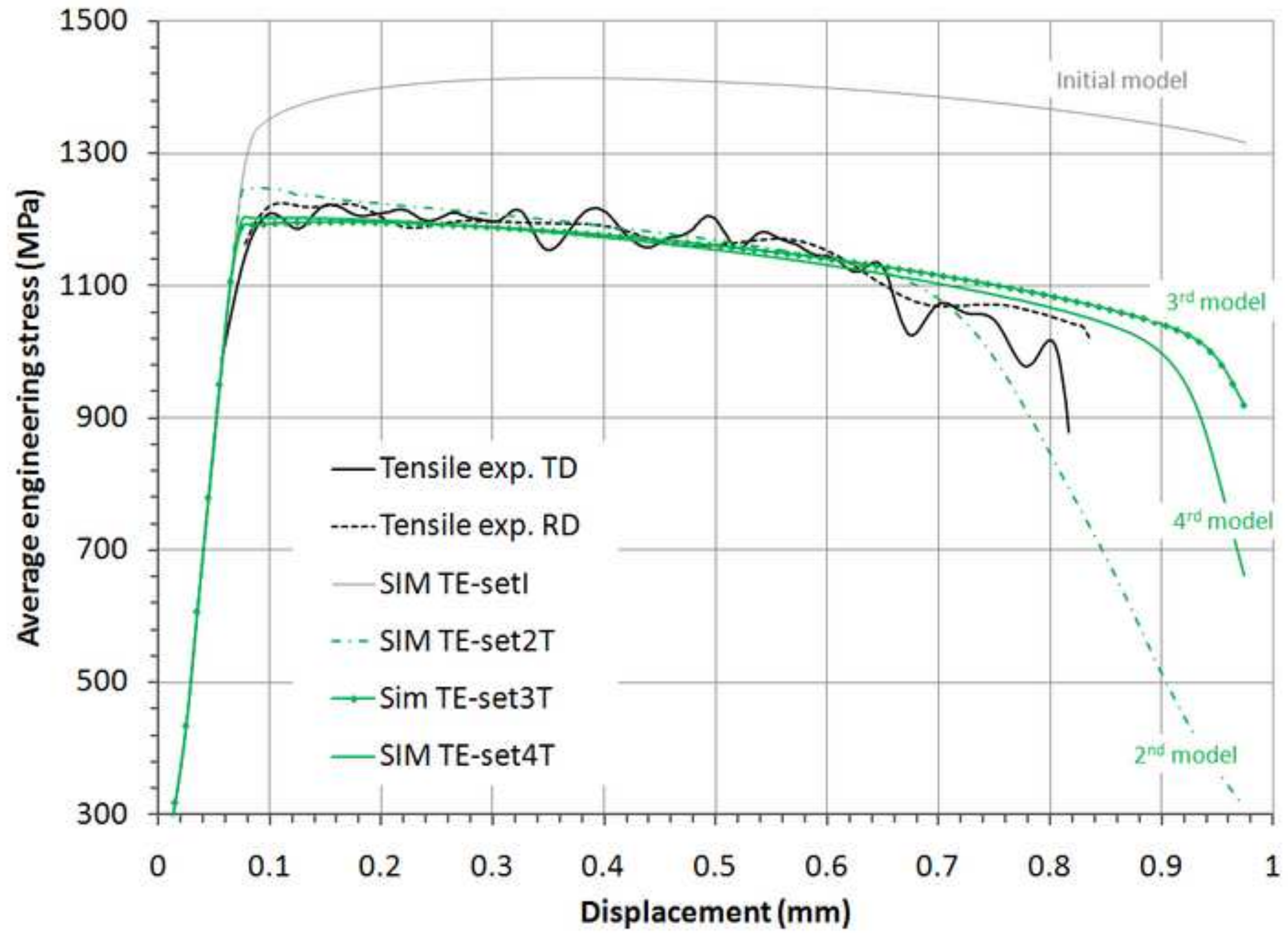




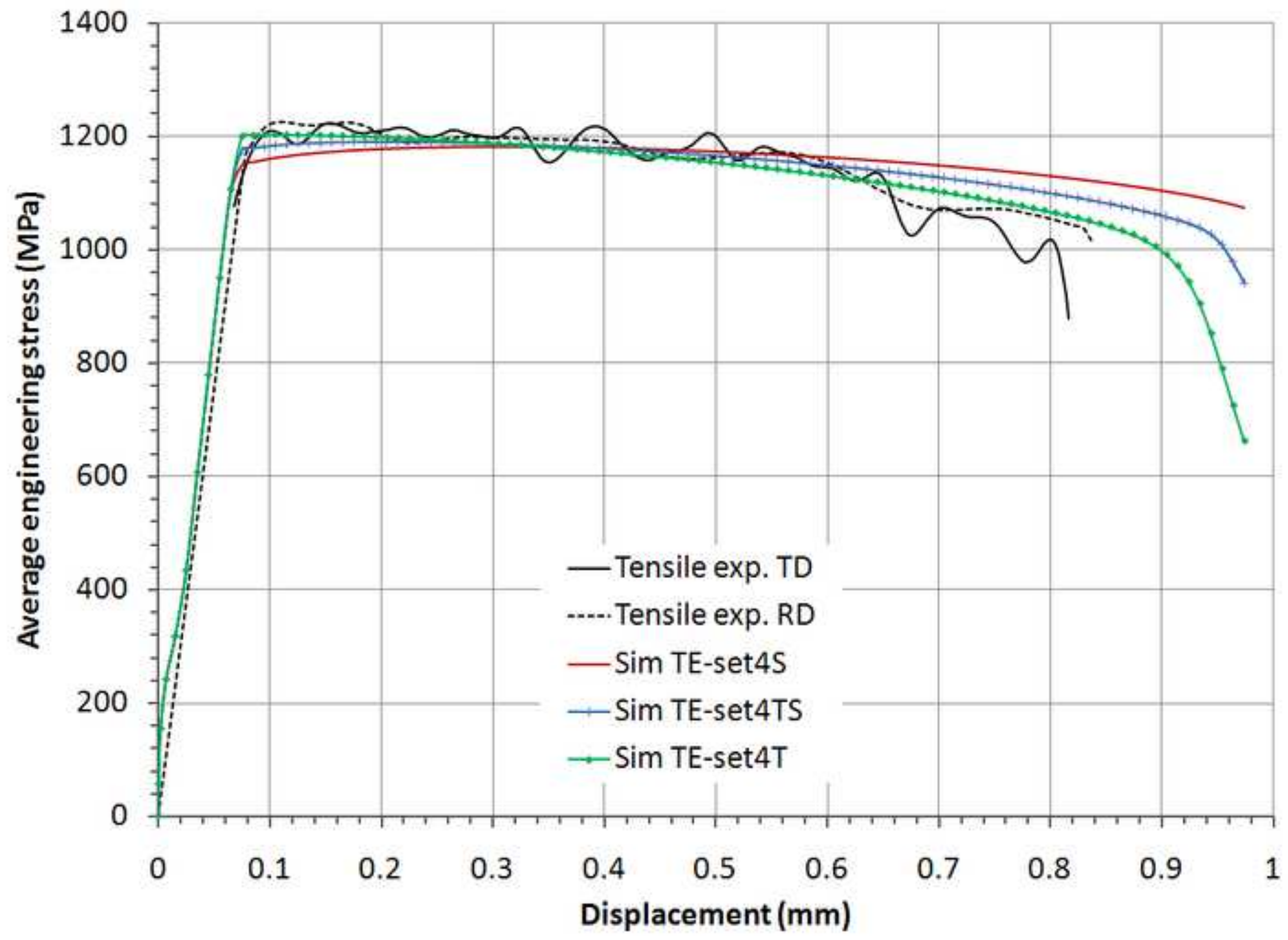




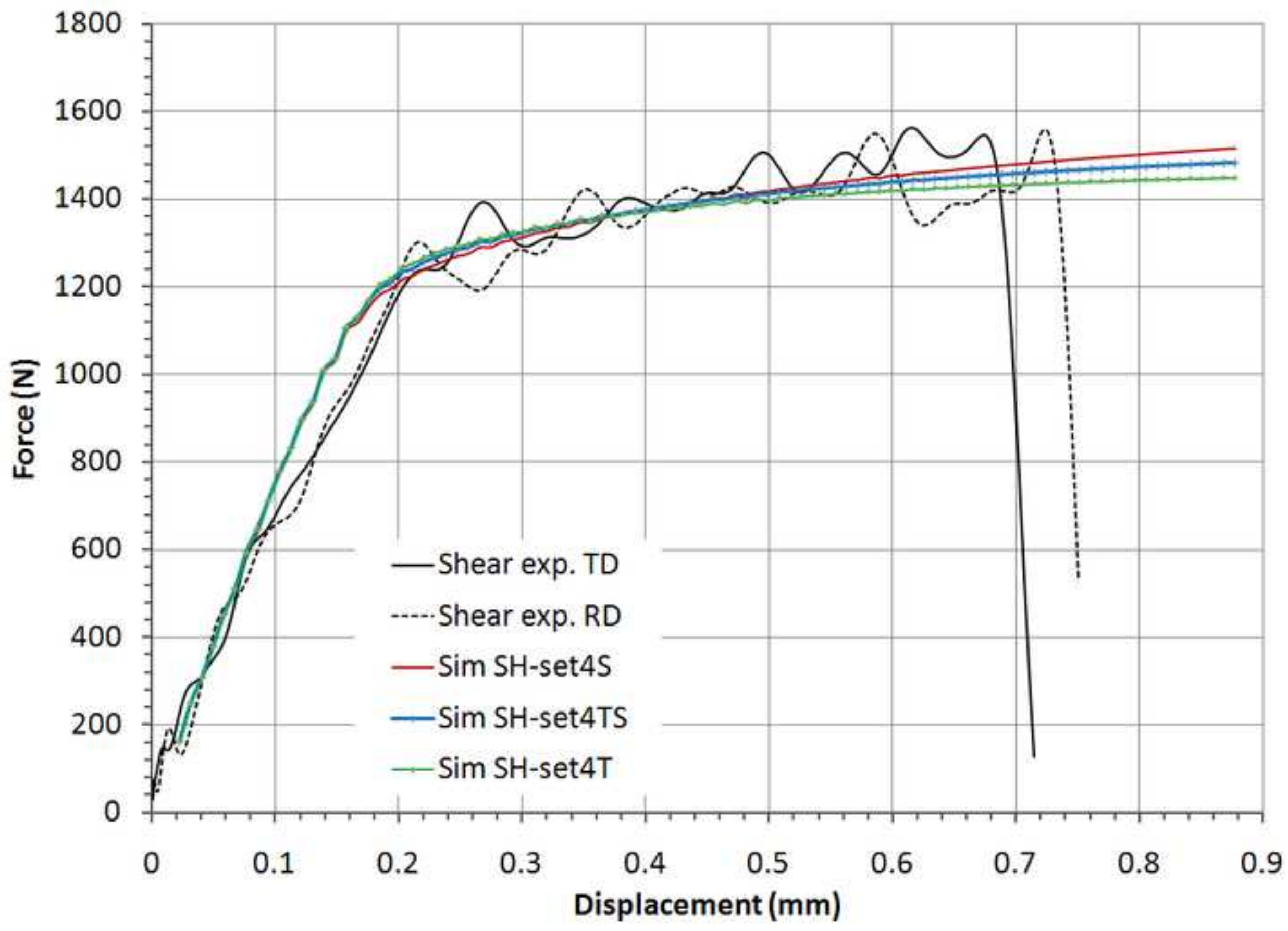




\section{FE - simulation}

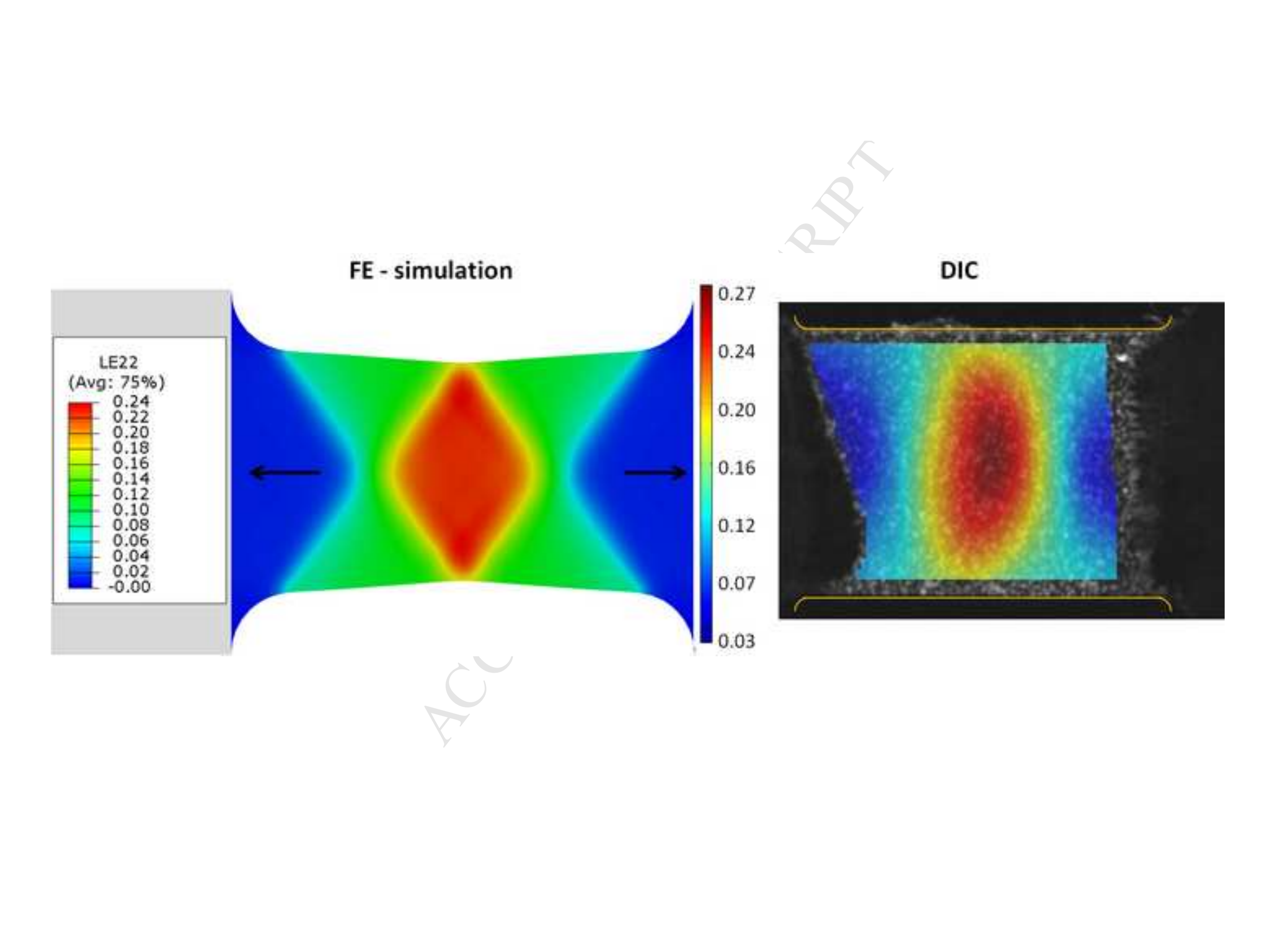

DIC
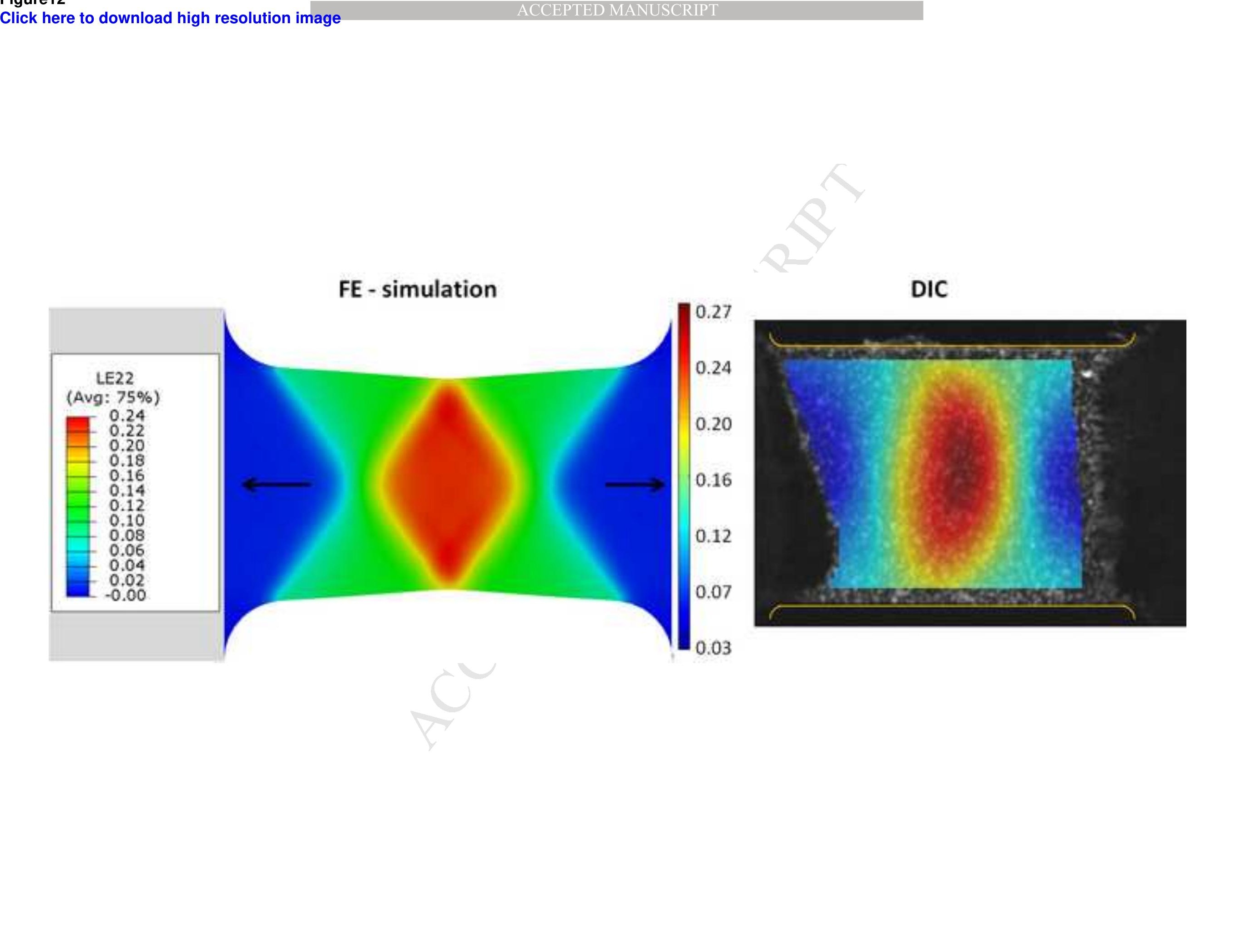


\section{FE - simulation}

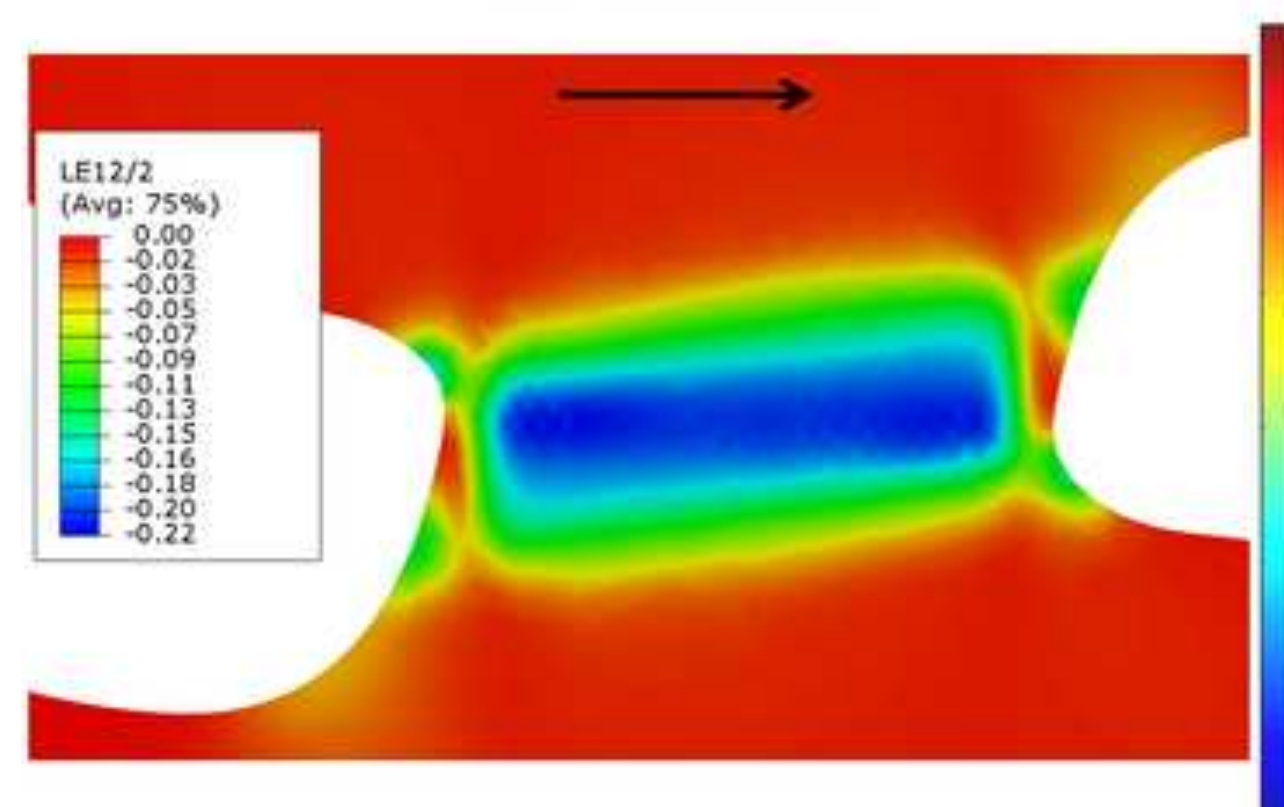

DIC

0.00
-0.04
-0.07
-0.11
-0.14
-0.18
-0.22

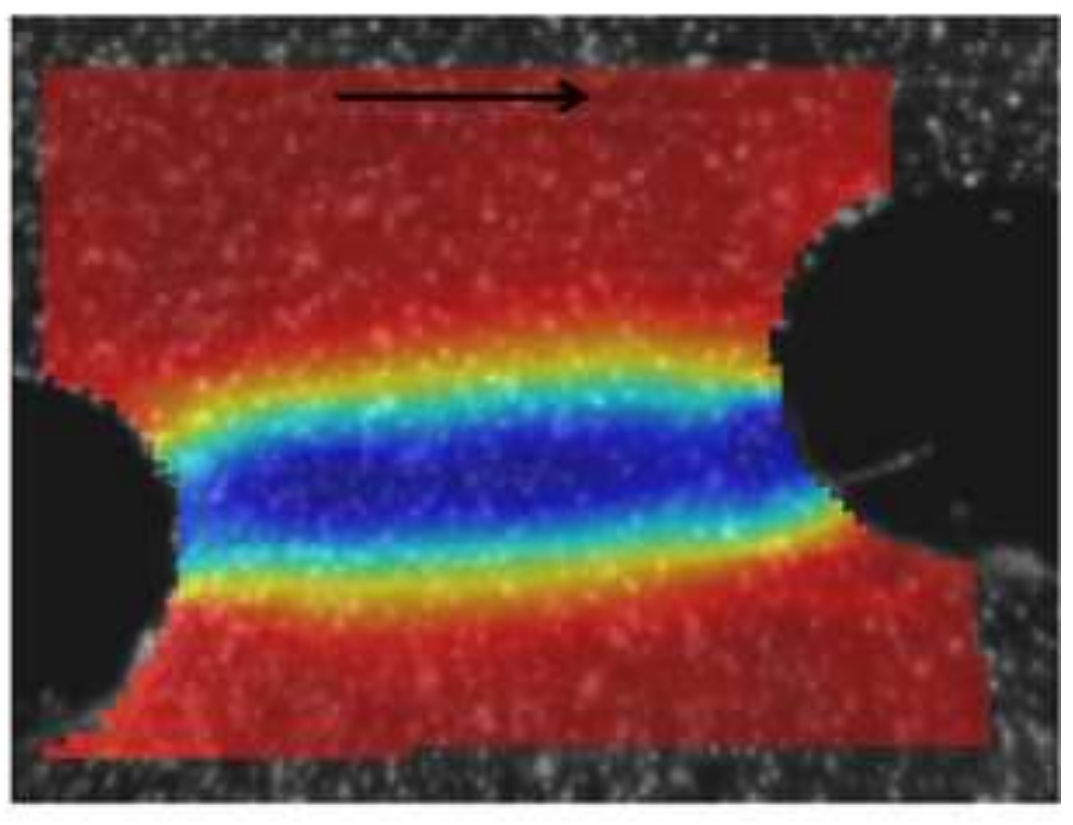




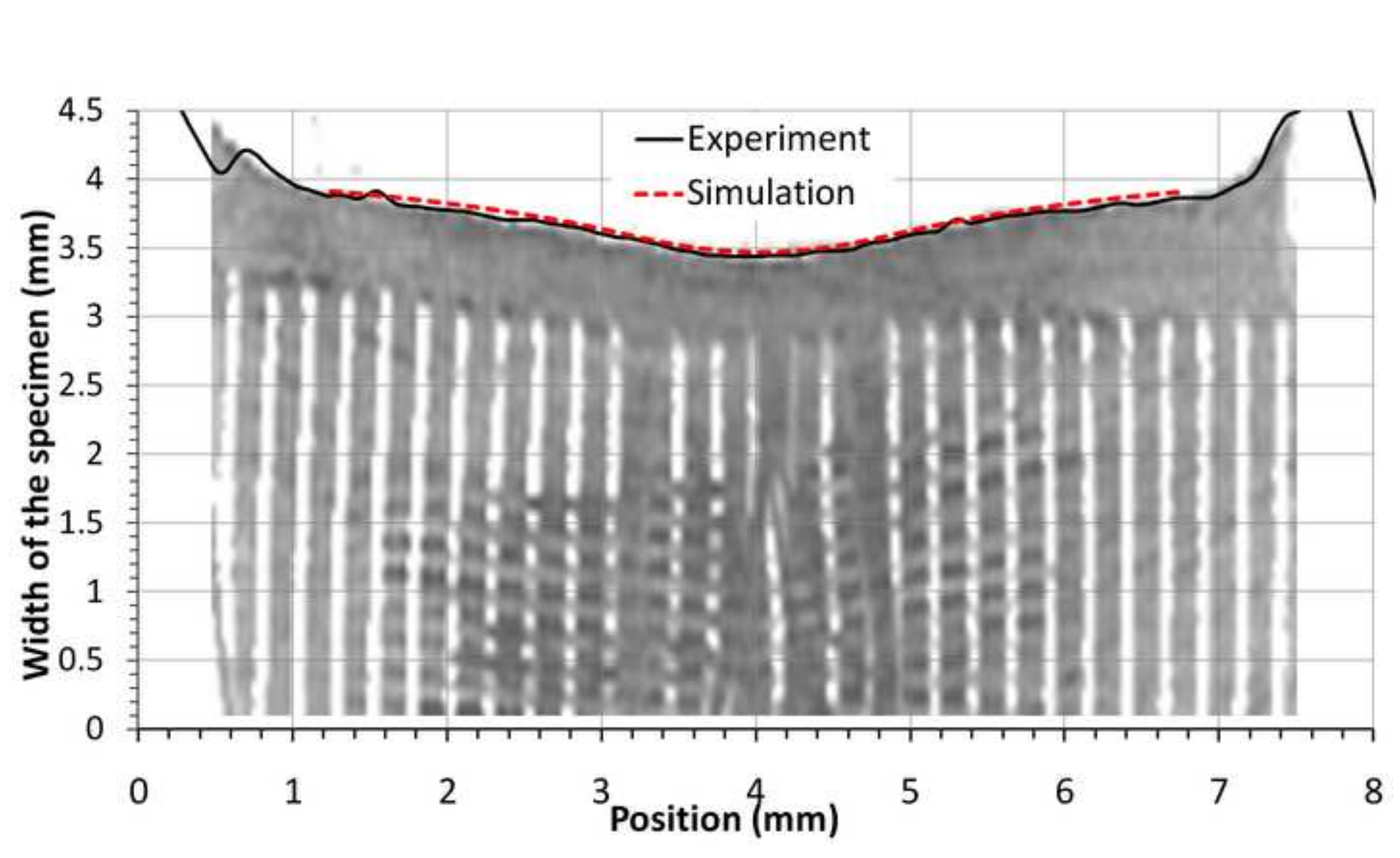

Che here

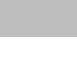

.

